University of Nebraska - Lincoln

DigitalCommons@University of Nebraska - Lincoln

October 2005

\title{
American Indian Treaties in the State Courts: A Guide to Treaty Citations from Opinions of the State Court Systems
}

Charles D. Bernholz

University of Nebraska-Lincoln, cbernholz2@unl.edu

Robert J. Weiner Jr.

Syracuse University College of Law, rjweiner@law.syr.edu

Follow this and additional works at: https://digitalcommons.unl.edu/libraryscience

Part of the Library and Information Science Commons

Bernholz, Charles D. and Weiner, Robert J. Jr., "American Indian Treaties in the State Courts: A Guide to Treaty Citations from Opinions of the State Court Systems" (2005). Faculty Publications, UNL Libraries. 13.

https://digitalcommons.unl.edu/libraryscience/13

This Article is brought to you for free and open access by the Libraries at University of Nebraska-Lincoln at DigitalCommons@University of Nebraska - Lincoln. It has been accepted for inclusion in Faculty Publications, UNL Libraries by an authorized administrator of DigitalCommons@University of Nebraska - Lincoln. 


\title{
American Indian treaties in the State Courts: A guide to treaty citations from opinions of the State Court systems
}

\author{
Charles D. Bernholz ${ }^{\mathrm{a}, *}$, Robert J. Weiner Jr. ${ }^{\mathrm{b}, 1}$ \\ ${ }^{a}$ Love Memorial Library, University of Nebraska, Lincoln, NE 68588, USA \\ ${ }^{\mathrm{b}}$ H. Douglas Barclay Law Library, Syracuse University College of Law, Syracuse, NY 13244, USA
}

Available online 14 July 2005

In five other guides, the 375 recognized American Indian treaties created between the tribes and the federal government were partitioned into three categories: those instruments that have been cited in the opinions of the United States Supreme Court; ${ }^{1}$ those treaties that have appeared before only a lower level of the federal court system, i.e., below the Supreme Court $^{2}$ or - as a special subset - before the Courts of Claims; ${ }^{3}$ and those contracts that have never been referenced in the opinions of any federal court. ${ }^{4}$

However, some of these obligatory documents, created between these sovereign entities, have been cited within proceedings at the State Court level, and it is this specific ensemble of cases that is presented in this guide. ${ }^{5}$

Early in the history of the United States, difficulties arose for States in their expectations of authority. Worcester v. Georgia ${ }^{6}$ demonstrated that the State of Georgia had no authority within Cherokee tribal territory, and since then - with only a few deviations - the United States Supreme Court has affirmed this principle of sovereignty separation.

In some situations, the degree of insulation from any potential State interference was assured to tribes in federal treaty negotiations. ${ }^{7}$ Nevertheless, over time, evolving federal Indian policy created an atmosphere that led to the creation of reservations and to the allotment program. The separation of tribes from non-Indian populations was reduced through this latter process, and the creation of new States from the Territories led to further questions regarding States'

\footnotetext{
* Corresponding author. Fax: +1 4024725131.

E-mail addresses: cbernholz2@unl.edu (C.D. Bernholz), rjweiner@law.syr.edu (R.J. Weiner).

${ }^{1}$ Fax: +1 3154439567.
} 
authority. The Kansas Indians ${ }^{8}$ case before the United States Supreme Court argued that the integration of Indians into the general population as a by-product of land allotment sales to Whites meant that State law should apply to all residents of the counties involved. The Court rejected this argument. ${ }^{9}$ It did so again in a similar taxation case involving three Seneca reservations in New York State. ${ }^{10}$ McClanahan v. Arizona State Tax Commission ${ }^{11}$ reiterateda century later - the Court's position on this "tradition of sovereignty:" preemption of State laws within Indian lands adheres to a federal policy of tribal sovereignty.

Other tribal-State concerns included issues regarding freedom from slavery (Gregory v. Baugh, Virginia) ${ }^{12}$ and freedom of religion in American Indian traditions (State v. Big Sheep, Montana, and State v. Brave Heart, South Dakota). ${ }^{13}$ While many cases involved conflicts over treaty parameters and cultural traditions, Montoya v. Bolack (New Mexico) ${ }^{14}$ was decided in favor of American Indians who claimed the right to vote in state elections.

The Metlakatla Indian Community v. Egan ${ }^{15}$ suit concerned the use by Alaska natives of salmon fish traps that violated State law. The Secretary of the Interior had authorized the use of fish traps by the Metlakatlans, ${ }^{16}$ as part of federal actions that initially had conveyed to them the use of the Annette Islands in southeastern Alaska. The appellants claimed that "the Alaska constitution and statutes prohibiting fish traps [were] not applicable to them because, in adopting the constitution, the people of Alaska disclaimed right or title in or jurisdiction over Indian fishing rights and that the Alaska Statehood Act reserved absolute jurisdiction and control over Indian fishing rights to the United States." ${ }^{17}$ The Supreme Court of Alaska determined that the federal government had not provided the Metlakatlans with any permanent rights via treaty, and that, even if there had been some federal protections, these provisions did not transfer upon Alaska attaining statehood. This judgment was vacated when it was subsequently established, in the United States Supreme Court, that the Secretary of the Interior was authorized to permit the use of fish traps by the Metlakatlans (Metlakatla Indian Community v. Egan $).{ }^{18}$

The concerns are almost limitless, from traditional matters like water rights (Byers v. Wewa-ne, Oregon $)^{19}$ and trespass (Strawberry Valley Cattle Co. v. Chipman, Utah) ${ }^{20}$ to modern issues such as the Indian Child Welfare Act (In re Baby Boy D, Oklahoma), ${ }^{21}$ gambling (State ex rel. May v. Seneca-Cayuga Tribe, Oklahoma), ${ }^{22}$ and traffic violations (State v. Webster, Wisconsin). ${ }^{23}$ Controversy over gathering rights ${ }^{24}$ has always been particularly intense, and the recent reliance upon treaty parameters in Minnesota v. Mille Lacs Band of Chippewa Indians ${ }^{25}$ is a demonstration of the contemporary usefulness and validity of these instruments. ${ }^{26}$

A number of cases demonstrate ongoing gathering rights conflicts at the State, as opposed to the federal, level. These actions concern hunting and fishing issues, but also extend to other related areas such as the harvesting of wild rice found in State v. Keezer (Minnesota). ${ }^{27}$ While contributing to the federal versus State jurisdictional debate, the tension between federal treaties protecting such tribal gathering rights and state conservation protections often frames the conflict.

For example, Table 1 contains six gathering rights cases, all argued before the Supreme Court of Idaho between 1943 and 1985, which refer to eleven federal treaties. ${ }^{28}$ These proceedings provide insight into the difficulties attached to these inquiries. 
Table 1

Indian treaties, listed by Department of State ratified treaty number, which have been referenced in the opinions of State Courts

\begin{tabular}{|c|c|c|c|c|c|c|c|}
\hline $\begin{array}{l}\text { Ratified } \\
\text { treaty } \\
\text { number }\end{array}$ & $\begin{array}{l}\text { Signatory } \\
\text { tribe(s) }\end{array}$ & $\begin{array}{l}\text { Treaty signing } \\
\text { date }\end{array}$ & $\begin{array}{l}\text { Kappler } \\
\text { page number }\end{array}$ & $\begin{array}{l}\text { Statutes } \\
\text { at large }\end{array}$ & Case title & Citation & Court \\
\hline 1 & $\begin{array}{l}\text { Cayuga; } \\
\text { Mohawk; } \\
\text { Oneida; } \\
\text { Onondaga; } \\
\text { Seneca; } \\
\text { Mahican }\end{array}$ & $\begin{array}{l}14 \text { September } \\
1722\end{array}$ & $\begin{array}{l}\text { EAID 9, 103; } \\
N Y 5,657\end{array}$ & - & $\begin{array}{l}\text { Gregory v. } \\
\text { Baugh (1827) }\end{array}$ & 25 Va. 611 & $\begin{array}{l}\text { Sup. Ct., } \\
\text { Va. }\end{array}$ \\
\hline 3 & $\begin{array}{l}\text { Cayuga; } \\
\text { Mohawk; } \\
\text { Oneida; } \\
\text { Onondaga; } \\
\text { Seneca; } \\
\text { Tuscarora }\end{array}$ & 4 July 1744 & $\begin{array}{l}\text { EAID 2, 77; } \\
\text { Franklin } 41\end{array}$ & - & $\begin{array}{l}\text { In re Baby } \\
\text { Boy D (1985) }\end{array}$ & 742 P.2d 1059 & $\begin{array}{l}\text { Sup. Ct., } \\
\text { Okla. }\end{array}$ \\
\hline 7 & $\begin{array}{l}\text { Cayuga; } \\
\text { Mohawk; } \\
\text { Oneida; } \\
\text { Onondaga; } \\
\text { Seneca; } \\
\text { Tuscarora; } \\
\text { Shawnee; } \\
\text { Delaware; } \\
\text { Mingo }\end{array}$ & $\begin{array}{l}5 \text { November } \\
1768\end{array}$ & $\begin{array}{l}\text { EAID 10, 541; } \\
N Y 8,111\end{array}$ & - & $\begin{array}{l}\text { Commonwealth } \\
\text { v. Coxe (1800) }\end{array}$ & 4 U.S. 170 & $\begin{array}{l}\text { Sup. Ct., } \\
\text { Pa. }\end{array}$ \\
\hline 7 & & $\begin{array}{l}5 \text { November } \\
1768\end{array}$ & $\begin{array}{l}\text { EAID 10, 541; } \\
N Y 8,111\end{array}$ & - & $\begin{array}{l}\text { Poor v. McClure } \\
(1874)\end{array}$ & 77 Рa. 214 & $\begin{array}{l}\text { Sup. Ct., } \\
\text { Pa. }\end{array}$ \\
\hline 9 & $\begin{array}{l}\text { Cayuga; } \\
\text { Mohawk; } \\
\text { Oneida; } \\
\text { Onondaga; } \\
\text { Seneca; } \\
\text { Tuscarora }\end{array}$ & 22 October 1784 & 5 & 7 Stat. 15 & $\begin{array}{l}\text { People ex rel. } \\
\text { Cayuga Nation } \\
\text { of Indians v. } \\
\text { Commissioners of } \\
\text { Land Office (1911) }\end{array}$ & 74 Misc. 154 & $\begin{array}{l}\text { Sup. Ct., } \\
\text { N.Y. }\end{array}$ \\
\hline
\end{tabular}




\begin{tabular}{|c|c|c|c|c|c|c|c|}
\hline & & & & & $\begin{array}{l}\text { Commissioners } \\
\text { of Land Office } \\
\text { (1912) }\end{array}$ & & \\
\hline 9 & & 22 October 1784 & 5 & 7 Stat. 15 & $\begin{array}{l}\text { Andrews v. } \\
\text { State (1948) }\end{array}$ & 192 Misc. 429 & $\begin{array}{l}\text { Ct. Cl., } \\
\text { N.Y. }\end{array}$ \\
\hline 9 & & 22 October 1784 & 5 & 7 Stat. 15 & $\begin{array}{l}\text { State v. Coffee } \\
\text { (1976) }\end{array}$ & 97 Idaho 905 & $\begin{array}{l}\text { Sup. Ct., } \\
\text { Idaho }\end{array}$ \\
\hline 9 & & 22 October 1784 & 5 & 7 Stat. 15 & $\begin{array}{l}\text { New York } \\
\text { State Department } \\
\text { of Taxation and } \\
\text { Finance v. } \\
\text { Bramhall (1997) }\end{array}$ & 235 A.D.2d 75 & $\begin{array}{l}\text { Sup. Ct., } \\
\text { N.Y. }\end{array}$ \\
\hline 10 & $\begin{array}{l}\text { Wyandot; } \\
\text { Delaware; } \\
\text { Chippewa; } \\
\text { Ottawa }\end{array}$ & 21 January 1785 & 6 & 7 Stat. 16 & $\begin{array}{l}\text { Brown v. Babbitt } \\
\text { Ford (1977) }\end{array}$ & 117 Ariz. 192 & $\begin{array}{l}\text { Ct. App., } \\
\text { Ariz. }\end{array}$ \\
\hline 11 & Cherokee & $\begin{array}{l}28 \text { November } \\
1785\end{array}$ & 8 & 7 Stat. 18 & $\begin{array}{l}\text { J \& M Aircraft } \\
\text { Mobile T Hangars, } \\
\text { Inc. v. Johnson County } \\
\text { Airport } \\
\text { Authority (2004) }\end{array}$ & $\begin{array}{l}269 \mathrm{Ga} . \\
\text { App. } 800\end{array}$ & $\begin{array}{l}\text { Ct. App., } \\
\text { Ga. }\end{array}$ \\
\hline 15 & $\begin{array}{l}\text { Wyandot; } \\
\text { Delaware; } \\
\text { Ottawa; } \\
\text { Chippewa; } \\
\text { Potawatomi; Sac }\end{array}$ & 9 January 1789 & 18 & 7 Stat. 28 & $\begin{array}{l}\text { Lewis v. Sac and } \\
\text { Fox Tribe } \\
\text { of Oklahoma } \\
\text { Housing Authority } \\
\text { (1994) }\end{array}$ & 896 P.2d 503 & $\begin{array}{l}\text { Sup. Ct., } \\
\text { Okla. }\end{array}$ \\
\hline 16 & $\begin{array}{l}\text { Cayuga; } \\
\text { Mohawk; } \\
\text { Oneida; } \\
\text { Onondaga; } \\
\text { Seneca; } \\
\text { Tuscarora }\end{array}$ & 9 January 1789 & 23 & 7 Stat. 33 & $\begin{array}{l}\text { People ex rel. } \\
\text { Cayuga Nation of } \\
\text { Indians v. } \\
\text { Commissioners of } \\
\text { Land Office (1912) }\end{array}$ & 152 A.D. 543 & $\begin{array}{l}\text { App. Div., } \\
\text { N.Y. }\end{array}$ \\
\hline
\end{tabular}




\begin{tabular}{|c|c|c|c|c|c|c|c|}
\hline 16 & & 9 January 1789 & 23 & 7 Stat. 33 & $\begin{array}{l}\text { Andrews v. } \\
\text { State (1948) }\end{array}$ & 192 Misc. 429 & $\begin{array}{l}\text { Ct. Cl., } \\
\text { N.Y. }\end{array}$ \\
\hline 16 & & 9 January 1789 & 23 & 7 Stat. 33 & $\begin{array}{l}\text { New York } \\
\text { State Department of } \\
\text { Taxation and } \\
\text { Finance v. } \\
\text { Bramhall (1997) }\end{array}$ & 235 A.D.2d 75 & $\begin{array}{l}\text { Sup. Ct., } \\
\text { N.Y. }\end{array}$ \\
\hline 21 & $\begin{array}{l}\text { Cayuga; } \\
\text { Mohawk; } \\
\text { Oneida; } \\
\text { Onondaga; } \\
\text { Seneca; } \\
\text { Tuscarora }\end{array}$ & $\begin{array}{l}11 \text { November } \\
1794\end{array}$ & 34 & 7 Stat. 44 & $\begin{array}{l}\text { Shongo v. } \\
\text { Miller (1899) }\end{array}$ & 45 A.D. 339 & $\begin{array}{l}\text { App. Div., } \\
\text { N.Y. }\end{array}$ \\
\hline 21 & & $\begin{array}{l}11 \text { November } \\
1794\end{array}$ & 34 & 7 Stat. 44 & $\begin{array}{l}\text { Sharp v. } \\
\text { Lancaster (1909) }\end{array}$ & 23 Okla. 349 & $\begin{array}{l}\text { Sup. Ct., } \\
\text { Okla. }\end{array}$ \\
\hline 21 & & $\begin{array}{l}11 \text { November } \\
1794\end{array}$ & 34 & 7 Stat. 44 & $\begin{array}{l}\text { People ex rel. } \\
\text { Cayuga Nation of } \\
\text { Indians v. } \\
\text { Commissioners } \\
\text { of Land Office } \\
\text { (1912) }\end{array}$ & 152 A.D. 543 & $\begin{array}{l}\text { App. Div., } \\
\text { N.Y. }\end{array}$ \\
\hline 21 & & $\begin{array}{l}11 \text { November } \\
1794\end{array}$ & 34 & 7 Stat. 44 & $\begin{array}{l}\text { Woodin v. } \\
\text { Seeley (1931) }\end{array}$ & 141 Misc. 207 & $\begin{array}{l}\text { County } \\
\text { Ct., N.Y. } \\
\text { Chautauqua }\end{array}$ \\
\hline 21 & & $\begin{array}{l}11 \text { November } \\
1794\end{array}$ & 34 & 7 Stat. 44 & $\begin{array}{l}\text { People ex rel. } \\
\text { Ray v. Martin } \\
\text { (1945) }\end{array}$ & 294 N.Y. 61 & $\begin{array}{l}\text { Ct. App., } \\
\text { N.Y. }\end{array}$ \\
\hline 21 & & $\begin{array}{l}11 \text { November } \\
1794\end{array}$ & 34 & 7 Stat. 44 & $\begin{array}{l}\text { Andrews v. } \\
\text { State (1948) }\end{array}$ & 192 Misc. 429 & $\begin{array}{l}\text { Ct. Cl., } \\
\text { N.Y. }\end{array}$ \\
\hline 21 & & $\begin{array}{l}11 \text { November } \\
1794\end{array}$ & 34 & 7 Stat. 44 & $\begin{array}{l}\text { Fischer v. Tebo } \\
(1959)\end{array}$ & 9 A.D. $2 d 470$ & $\begin{array}{l}\text { App. Div., } \\
\text { N.Y. }\end{array}$ \\
\hline 21 & & $\begin{array}{l}11 \text { November } \\
1794\end{array}$ & 34 & 7 Stat. 44 & $\begin{array}{l}\text { Pierce v. State } \\
\text { Tax Commis- } \\
\text { sion (1968) }\end{array}$ & 29 A.D. $2 d 124$ & $\begin{array}{l}\text { Ct. App., } \\
\text { N.Y. }\end{array}$ \\
\hline
\end{tabular}




\section{Chippewa;}

Potawatomi;

Miami;

Eel River; Wea;

Kickapoo;

Piankashaw;

Kaskaskia

7 Stat. 44

People v.

Edwards (1980)

People v.

Gunton (1993)

New York

State Department

of Taxation

and Finance v.

Bramhall (1997)

7 Stat. 49

Lemieux v. Agate

Land Co. (1927)

Hernik v.

Director of

Highways

(1959)

People v. Le

Blanc (1976)

State v. Keezer

(1980)

St. Regis Tribe

of Mohawk

Indians v. State

(1956)

St. Regis Tribe

of Mohawk

Indians v. State

(1957)
214 N.W. 454

Sup. Ct., Ohio

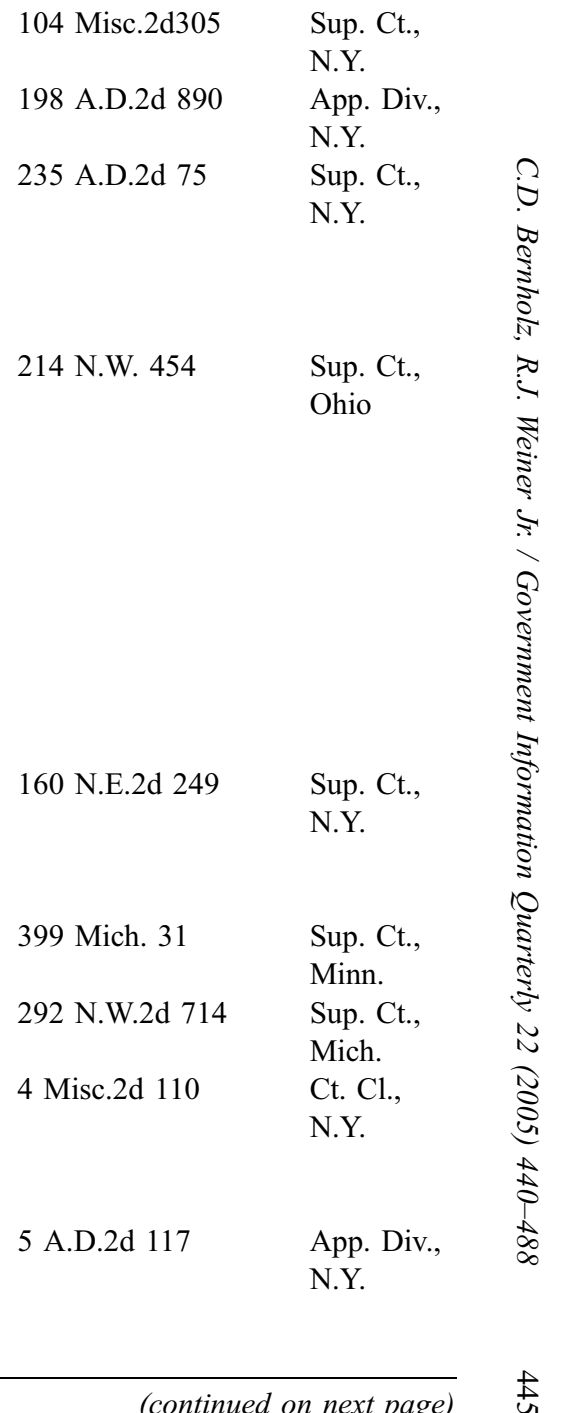




31 May 1796

45

31 May 1796

\section{5}

15 September

1027

27

Seneca

1797

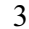

45

Choctaw

Wyandot;

Ottawa;

Chippewa;

Munsee;

Delaware;

Shawnee;

54 Potawatomi

Ottawa;

Chippewa;

Wyandot;

56 Potawatomi

Ottawa;

Potawatomi;

Wyandot;

Shawnee
15 September 1027
1797

$15 \quad$ September 1027

1797

17 December 56 1801

4 July 1805

77

17 November

1807

25 November 99 1808

7 Stat. 55

7 Stat. 55

St. Regis Tribe

of Mohawk

Indians v. State

(1958)

Fischer v. Tebo

(1959)

7 Stat. 601;

American State

Papers: Indian

Affairs 1, 627

7 Stat. 601;

American State

Papers: Indian

Affairs 1, 627

7 Stat. 601;

American State

Papers: Indian

Affairs 1, 627

7 Stat. 66

7 Stat. 87

State v. Tulee

(1941)

Wood v. City of

Salamanca (1942)

Department of

Game v.

Puyallup Tribe,

Inc. (1967)

Brown v. Babbitt

Ford (1977)

People v. Le

Blanc (1976)

7 Stat. 105

People v. Le

Blanc (1976)

People v. Le

Blanc (1976)

7 Stat. 112

5 N.Y.2d $24 \quad$ Sup. Ct.,

N.Y.

9 A.D. $2 \mathrm{~d} 470$

App. Div.,

N.Y.

7 Wash.2d 124

Sup. Ct.,

Wash.

289 N.Y. 279

Sup. Ct.,

N.Y.

70 Wash.2d

245

Sup. Ct.,

Wash.

117 Ariz. 192

Ct. App.,

Ariz.

399 Mich. 31

Sup. Ct.,

Mich.
Sup. Ct. Mich. 


\section{Seneca;}

Miami;

Potawatomi;

Ottawa:

Blanchard's

\section{Fork; Kickapoo}

Wyandot;

29 September

Delaware;

Shawnee;

Potawatomi;

Ottawa;

Chippewa

90

29 September 1817
Sturdevant v. State (1977)

76 Wis.2d 247

399 Mich. 31

Blanc (1976)

7 Stat. 160

Children of

Chippewa,

Ottawa and

Potawatomi

Tribes v.

Regents of

University of

Michigan (1981)

7 Stat. 160

State ex rel.

May v.

Seneca-Cayuga

Tribe (1985)

State ex rel.

May v.

Seneca-Cayuga

Tribe (1985)

7 Stat. 203
104 Mich.

App. 482

Ct. App., Mich.

711 P.2d 77

Sup. Ct., Okla.

711 P.2d 77

Sup. Ct.,

Okla.

136 Mich.

288 


\begin{tabular}{|c|c|c|c|c|c|c|c|}
\hline 109 & & $\begin{array}{l}24 \text { September } \\
1819\end{array}$ & 185 & 7 Stat. 203 & $\begin{array}{l}\text { People v. Le } \\
\text { Blanc (1976) }\end{array}$ & 399 Mich. 31 & $\begin{array}{l}\text { Sup. Ct., } \\
\text { Mich. }\end{array}$ \\
\hline 110 & Chippewa & 16 June 1820 & 187 & 7 Stat. 206 & $\begin{array}{l}\text { Spaulding v. } \\
\text { Chandler (1890) }\end{array}$ & 84 Mich. 140 & $\begin{array}{l}\text { Sup. Ct., } \\
\text { Mich. }\end{array}$ \\
\hline 110 & & 16 June 1820 & 187 & 7 Stat. 206 & $\begin{array}{l}\text { People v. Le } \\
\text { Blanc (1974) }\end{array}$ & $\begin{array}{l}55 \text { Mich. } \\
\text { App. } 684\end{array}$ & $\begin{array}{l}\text { Ct. App., } \\
\text { Mich. }\end{array}$ \\
\hline 115 & Choctaw & 18 October 1820 & 191 & 7 Stat. 210 & $\begin{array}{l}\text { Ned v. } \\
\text { Countiss (1922) }\end{array}$ & 84 Okla. 138 & $\begin{array}{l}\text { Sup. Ct., } \\
\text { Okla. }\end{array}$ \\
\hline 116 & Creek & 8 January 1821 & 195 & 7 Stat. 215 & $\begin{array}{l}\text { Minter v. State } \\
\text { (1924) }\end{array}$ & 158 Ga. 127 & $\begin{array}{l}\text { Sup. Ct., } \\
\text { Ga. }\end{array}$ \\
\hline 117 & $\begin{array}{l}\text { Ottawa; } \\
\text { Chippewa; } \\
\text { Potawatomi }\end{array}$ & 29 August 1821 & 198 & 7 Stat. 218 & $\begin{array}{l}\text { Steeple v. } \\
\text { Downing (1879) }\end{array}$ & 60 Ind. 478 & $\begin{array}{l}\text { Sup. Ct., } \\
\text { Ind. }\end{array}$ \\
\hline 117 & & 29 August 1821 & 198 & 7 Stat. 218 & $\begin{array}{l}\text { People v. Le } \\
\text { Blanc (1976) }\end{array}$ & 399 Mich. 31 & $\begin{array}{l}\text { Sup. Ct., } \\
\text { Mich. }\end{array}$ \\
\hline 123 & Quapaw & $\begin{array}{l}15 \text { November } \\
1824\end{array}$ & 210 & 7 Stat. 232 & $\begin{array}{l}\text { State ex rel. } \\
\text { May v. } \\
\text { Seneca-Cayuga } \\
\text { Tribe (1985) }\end{array}$ & 711 P.2d 77 & $\begin{array}{l}\text { Sup. Ct., } \\
\text { Okla. }\end{array}$ \\
\hline 123.1 & Quapaw & 13 May 1833 & 395 & 7 Stat. 424 & $\begin{array}{l}\text { State ex rel. } \\
\text { May v. } \\
\text { Seneca-Cayuga } \\
\text { Tribe (1985) }\end{array}$ & 711 P.2d 77 & $\begin{array}{l}\text { Sup. Ct., } \\
\text { Okla. }\end{array}$ \\
\hline 125 & Creek & $\begin{array}{l}12 \text { February } \\
1825\end{array}$ & 214 & 7 Stat. 237 & $\begin{array}{l}\text { J \& M Aircraft } \\
\text { Mobile T } \\
\text { Hangars, Inc. v. } \\
\text { Johnson } \\
\text { County Airport } \\
\text { Authority (2004) }\end{array}$ & $\begin{array}{l}269 \mathrm{Ga} . \\
\text { App. } 800\end{array}$ & $\begin{array}{l}\text { Ct. App., } \\
\text { Ga. }\end{array}$ \\
\hline 127 & Kansa & 3 June 1825 & 222 & 7 Stat. 244 & $\begin{array}{l}\text { Stevens v. } \\
\text { Smith (1864) }\end{array}$ & 2 Kan. 243 & $\begin{array}{l}\text { Sup. Ct., } \\
\text { Kan. }\end{array}$ \\
\hline 127 & & 3 June 1825 & 222 & 7 Stat. 244 & $\begin{array}{l}\text { Brown v. } \\
\text { Belmarde (1864) }\end{array}$ & 3 Kan. 41 & $\begin{array}{l}\text { Sup. Ct., } \\
\text { Kan. }\end{array}$ \\
\hline 127 & & 3 June 1825 & 222 & 7 Stat. 244 & $\begin{array}{l}\text { Brader v. } \\
\text { James (1916) }\end{array}$ & 49 Okla. 734 & $\begin{array}{l}\text { Sup. Ct., } \\
\text { Okla. }\end{array}$ \\
\hline
\end{tabular}




\begin{tabular}{|c|c|c|c|c|c|c|c|}
\hline 139 & $\begin{array}{l}\text { Sioux; } \\
\text { Chippewa; } \\
\text { Sac and Fox; } \\
\text { Menominee; } \\
\text { Iowa; } \\
\text { Winnebago; } \\
\text { Ottawa; } \\
\text { Potawatomi }\end{array}$ & 19 August 1825 & 250 & 7 Stat. 272 & $\begin{array}{l}\text { State v. } \\
\text { Keezer (1980) }\end{array}$ & 292 N.W.2d 714 & $\begin{array}{l}\text { Sup. Ct., } \\
\text { Minn. }\end{array}$ \\
\hline 139 & & 19 August 1825 & 250 & 7 Stat. 272 & $\begin{array}{l}\text { State v. Lowe } \\
\text { (1982) }\end{array}$ & 109 Wis.2d 633 & $\begin{array}{l}\text { Ct. App., } \\
\text { Wis. }\end{array}$ \\
\hline 144 & Creek & 24 January 1826 & 264 & 7 Stat. 286 & $\begin{array}{l}\text { Minter v. } \\
\text { State (1924) }\end{array}$ & $158 \mathrm{Ga} .127$ & $\begin{array}{l}\text { Sup. Ct., } \\
\text { Ga. }\end{array}$ \\
\hline 146 & Potawatomi & $\begin{array}{l}16 \text { October } \\
1826\end{array}$ & 273 & $\begin{array}{l}7 \text { Stat. } \\
295\end{array}$ & $\begin{array}{l}\text { Ashley v. } \\
\text { Eberts (1864) }\end{array}$ & 22 Ind. 55 & $\begin{array}{l}\text { Sup. Ct., } \\
\text { Ind. }\end{array}$ \\
\hline 152 & $\begin{array}{l}\text { Cherokee: } \\
\text { Western }\end{array}$ & $\begin{array}{l}6 \text { May } \\
1828\end{array}$ & 288 & $\begin{array}{l}7 \text { Stat. } \\
311\end{array}$ & $\begin{array}{l}\text { Strawberry } \\
\text { Valley Cattle } \\
\text { Co. v. Chipman } \\
\text { (1896) }\end{array}$ & 13 Utah 454 & $\begin{array}{l}\text { Sup. Ct., } \\
\text { Utah }\end{array}$ \\
\hline 152 & & $\begin{array}{l}6 \text { May } \\
1828\end{array}$ & 288 & $\begin{array}{l}7 \text { Stat. } \\
311\end{array}$ & $\begin{array}{l}\text { Vickery v. } \\
\text { Yahola } \\
\text { Sand and } \\
\text { Gravel Co. } \\
(1932)\end{array}$ & 158 Okla. 120 & $\begin{array}{l}\text { Sup. Ct., } \\
\text { Okla. }\end{array}$ \\
\hline 152 & & $\begin{array}{l}6 \text { May } \\
1828\end{array}$ & 288 & $\begin{array}{l}7 \text { Stat. } \\
311\end{array}$ & $\begin{array}{l}\text { Aladdin } \\
\text { Petroleum } \\
\text { Corp. v. State } \\
\text { ex rel. Commis- } \\
\text { sioners of Land } \\
\text { Office (1948) }\end{array}$ & 200 Okla. 134 & $\begin{array}{l}\text { Sup. Ct., } \\
\text { Okla. }\end{array}$ \\
\hline 152 & & $\begin{array}{l}6 \text { May } \\
1828\end{array}$ & 288 & $\begin{array}{l}7 \text { Stat. } \\
311\end{array}$ & $\begin{array}{l}\text { State v. McCoy } \\
\text { (1963) }\end{array}$ & 63 Wash.2d 421 & $\begin{array}{l}\text { Sup. Ct., } \\
\text { Mich. }\end{array}$ \\
\hline
\end{tabular}




\begin{tabular}{|c|c|c|c|c|c|c|c|}
\hline 152.1 & $\begin{array}{l}\text { Cherokee: } \\
\text { Western }\end{array}$ & $\begin{array}{l}14 \text { February } \\
1833\end{array}$ & 385 & $\begin{array}{l}7 \text { Stat. } \\
414\end{array}$ & $\begin{array}{l}\text { Aladdin } \\
\text { Petroleum } \\
\text { Corp. v. State } \\
\text { ex rel. Commis- } \\
\text { sioners of Land } \\
\text { Office (1948) }\end{array}$ & 200 Okla. 134 & $\begin{array}{l}\text { Sup. Ct., } \\
\text { Okla. }\end{array}$ \\
\hline 152.1 & & $\begin{array}{l}14 \text { February } \\
1833\end{array}$ & 385 & $\begin{array}{l}7 \text { Stat. } \\
414\end{array}$ & $\begin{array}{l}\text { Vickery v. } \\
\text { Yahola Sand } \\
\text { and Gravel } \\
\text { Co. (1932) }\end{array}$ & 158 Okla. 120 & $\begin{array}{l}\text { Sup. Ct., } \\
\text { Okla. }\end{array}$ \\
\hline 154 & Potawatomi & $\begin{array}{l}20 \text { September } \\
1828\end{array}$ & 294 & $\begin{array}{l}7 \text { Stat. } \\
317\end{array}$ & $\begin{array}{l}\text { People v. } \\
\text { Gebhard (1908) }\end{array}$ & 151 Mich. 192 & $\begin{array}{l}\text { Sup. Ct., } \\
\text { Mich. }\end{array}$ \\
\hline 155 & $\begin{array}{l}\text { Chippewa; } \\
\text { Ottawa; } \\
\text { Potawatomi }\end{array}$ & $\begin{array}{l}29 \text { July } \\
1829\end{array}$ & 297 & $\begin{array}{l}7 \text { Stat. } \\
320\end{array}$ & $\begin{array}{l}\text { Lomax v. } \\
\text { Pickering (1897) }\end{array}$ & 165 Ill. 431 & $\begin{array}{l}\text { Sup. Ct., } \\
\text { Ill. }\end{array}$ \\
\hline 155 & & $\begin{array}{l}29 \text { July } \\
1829\end{array}$ & 297 & $\begin{array}{l}7 \text { Stat. } \\
320\end{array}$ & $\begin{array}{l}\text { People v. } \\
\text { Gebhard (1908) }\end{array}$ & 151 Mich. 192 & $\begin{array}{l}\text { Sup. Ct., } \\
\text { Mich. }\end{array}$ \\
\hline 160 & Choctaw & $\begin{array}{l}27 \text { September } \\
1830\end{array}$ & 310 & $\begin{array}{l}7 \text { Stat. } \\
333\end{array}$ & $\begin{array}{l}\text { Godfrey v. Iowa } \\
\text { Land and } \\
\text { Trust Co. (1908) }\end{array}$ & 95 P. 792 & $\begin{array}{l}\text { Sup. Ct., } \\
\text { Okla. }\end{array}$ \\
\hline 160 & & $\begin{array}{l}27 \text { September } \\
1830\end{array}$ & 310 & $\begin{array}{l}7 \text { Stat. } \\
333\end{array}$ & $\begin{array}{l}\text { Ned v. Countiss } \\
\text { (1922) }\end{array}$ & 84 Okla. 138 & $\begin{array}{l}\text { Sup. Ct., } \\
\text { Okla. }\end{array}$ \\
\hline 160 & & $\begin{array}{l}27 \text { September } \\
1830\end{array}$ & 310 & $\begin{array}{l}7 \text { Stat. } \\
333\end{array}$ & $\begin{array}{l}\text { Taylor v. } \\
\text { Johnson (1923) }\end{array}$ & 92 Okla. 145 & $\begin{array}{l}\text { Sup. Ct., } \\
\text { Okla. }\end{array}$ \\
\hline 160 & & $\begin{array}{l}27 \text { September } \\
1830\end{array}$ & 310 & $\begin{array}{l}7 \text { Stat. } \\
333\end{array}$ & $\begin{array}{l}\text { Sampson v. } \\
\text { Stapleton (1916) }\end{array}$ & 55 Okla. 547 & $\begin{array}{l}\text { Sup. Ct., } \\
\text { Okla. }\end{array}$ \\
\hline 160 & & $\begin{array}{l}27 \text { September } \\
1830\end{array}$ & 310 & $\begin{array}{l}7 \text { Stat. } \\
333\end{array}$ & $\begin{array}{l}\text { Wrigley v. } \\
\text { McCoy (1917) }\end{array}$ & 73 Okla. 161 & $\begin{array}{l}\text { Sup. Ct., } \\
\text { Okla. }\end{array}$ \\
\hline 160 & & $\begin{array}{l}27 \text { September } \\
1830\end{array}$ & 310 & $\begin{array}{l}7 \text { Stat. } \\
333\end{array}$ & $\begin{array}{l}\text { Ex parte } \\
\text { Nowabbi (1936) }\end{array}$ & $\begin{array}{l}60 \text { Okla. } \\
\text { Crim. } 111\end{array}$ & $\begin{array}{l}\text { Ct. Crim. } \\
\text { App., Okla. }\end{array}$ \\
\hline 160 & & $\begin{array}{l}27 \text { September } \\
1830\end{array}$ & 310 & $\begin{array}{l}7 \text { Stat. } \\
333\end{array}$ & $\begin{array}{l}\text { Tubby v. } \\
\text { State (1976) }\end{array}$ & 327 So. $2 d 272$ & $\begin{array}{l}\text { Sup. Ct., } \\
\text { Miss. }\end{array}$ \\
\hline 160 & & $\begin{array}{l}27 \text { September } \\
1830\end{array}$ & 310 & $\begin{array}{l}7 \text { Stat. } \\
333\end{array}$ & $\begin{array}{l}\text { Wildcatt v. } \\
\text { Smith (1984) }\end{array}$ & 311 N.C. 397 & $\begin{array}{l}\text { Ct. App., } \\
\text { N.C. }\end{array}$ \\
\hline
\end{tabular}




\begin{tabular}{|c|c|c|c|c|c|c|c|}
\hline 161 & Menominee & $\begin{array}{l}8 \text { February } \\
1831\end{array}$ & 319 & $\begin{array}{l}7 \text { Stat. } \\
342\end{array}$ & $\begin{array}{l}\text { Sturdevant v. } \\
\text { State (1977) }\end{array}$ & 76 Wis.2d 247 & $\begin{array}{l}\text { Sup. Ct., } \\
\text { Wis. }\end{array}$ \\
\hline 162 & Seneca & $\begin{array}{l}28 \text { February } \\
1831\end{array}$ & 325 & $\begin{array}{l}7 \text { Stat. } \\
348\end{array}$ & $\begin{array}{l}\text { State ex rel. } \\
\text { May v. } \\
\text { Seneca-Cayuga } \\
\text { Tribe (1985) }\end{array}$ & 711 P.2d 77 & $\begin{array}{l}\text { Sup. Ct., } \\
\text { Okla. }\end{array}$ \\
\hline 162 & & $\begin{array}{l}28 \text { February } \\
1831\end{array}$ & 325 & $\begin{array}{l}7 \text { Stat. } \\
348\end{array}$ & $\begin{array}{l}\text { Hanes v. } \\
\text { State (1998) }\end{array}$ & 973 P. 2 d 330 & $\begin{array}{l}\text { Ct. Crim. } \\
\text { App., Okla. }\end{array}$ \\
\hline 163 & $\begin{array}{l}\text { Seneca: Mixed; } \\
\text { Shawnee }\end{array}$ & $\begin{array}{l}20 \text { July } \\
1831\end{array}$ & 327 & 7 Stat. 351 & $\begin{array}{l}\text { State ex rel. } \\
\text { May v. } \\
\text { Seneca-Cayuga } \\
\text { Tribe (1985) }\end{array}$ & 711 P.2d 77 & $\begin{array}{l}\text { Sup. Ct., } \\
\text { Okla. }\end{array}$ \\
\hline 163 & & 20 July 1831 & 327 & 7 Stat. 351 & $\begin{array}{l}\text { Hanes v. State } \\
\text { (1998) }\end{array}$ & 973 P.2d 330 & $\begin{array}{l}\text { Ct. Crim. } \\
\text { App., Okla. }\end{array}$ \\
\hline 164 & Shawnee & 8 August 1831 & 331 & 7 Stat. 355 & $\begin{array}{l}\text { In re Oyler } \\
(1994)\end{array}$ & 256 Kan. 589 & $\begin{array}{l}\text { Sup. Ct., } \\
\text { Kan. }\end{array}$ \\
\hline 164 & & 8 August 1831 & 331 & 7 Stat. 355 & $\begin{array}{l}\text { Pettit v. } \\
\text { Pettit (1858) }\end{array}$ & 32 Ala. 288 & $\begin{array}{l}\text { Sup. Ct., } \\
\text { Ala. }\end{array}$ \\
\hline 173 & Chickasaw & 20 October 1832 & 356 & 7 Stat. 381 & $\begin{array}{l}\text { Turney v. } \\
\text { Marion County } \\
\text { Bd. Of } \\
\text { Education (1985) }\end{array}$ & $\begin{array}{l}481 \text { So. } \\
\text { 2d } 770\end{array}$ & $\begin{array}{l}\text { Sup. Ct., } \\
\text { Miss. }\end{array}$ \\
\hline 179 & Menominee & 27 October 1832 & 377 & 7 Stat. 405 & $\begin{array}{l}\text { State v. Davids } \\
\text { (1995) }\end{array}$ & $\begin{array}{l}194 \text { Wis. } \\
\text { 2d } 386\end{array}$ & $\begin{array}{l}\text { Sup. Ct., } \\
\text { Wis. }\end{array}$ \\
\hline 181 & $\begin{array}{l}\text { Seneca; } \\
\text { Seneca: } \\
\text { Mixed; } \\
\text { Shawnee }\end{array}$ & $\begin{array}{l}29 \text { December } \\
1832\end{array}$ & 383 & 7 Stat. 411 & $\begin{array}{l}\text { State ex rel. } \\
\text { May v. } \\
\text { Seneca-Cayuga } \\
\text { Tribe (1985) }\end{array}$ & 711 P.2d 77 & $\begin{array}{l}\text { Sup. Ct., } \\
\text { Okla. }\end{array}$ \\
\hline 181 & & $\begin{array}{l}29 \text { December } \\
1832\end{array}$ & 383 & 7 Stat. 411 & $\begin{array}{l}\text { Hanes v. State } \\
\text { (1998) }\end{array}$ & 973 P.2d 330 & $\begin{array}{l}\text { Ct. Crim. } \\
\text { App., Okla. }\end{array}$ \\
\hline
\end{tabular}




\begin{tabular}{|c|c|c|c|}
\hline 182 & $\begin{array}{l}\text { Cherokee: } \\
\text { Western }\end{array}$ & $\begin{array}{l}14 \text { February } \\
1833\end{array}$ & 385 \\
\hline 182 & & $\begin{array}{l}14 \text { February } \\
1833\end{array}$ & 385 \\
\hline 183 & Creek & $\begin{array}{l}14 \text { February } \\
1833\end{array}$ & 388 \\
\hline 186 & Quapaw & 13 May 1833 & 395 \\
\hline 191 & Chickasaw & 24 May 1834 & 418 \\
\hline 198 & $\begin{array}{l}\text { Comanche; } \\
\text { Wichita; } \\
\text { Cherokee; } \\
\text { Muskogee; } \\
\text { Choctaw; } \\
\text { Osage; } \\
\text { Seneca; Quapaw }\end{array}$ & 24 August 1835 & 435 \\
\hline 199 & Cherokee & $\begin{array}{l}29 \text { December } \\
1835\end{array}$ & 439 \\
\hline 199 & & $\begin{array}{l}29 \text { December } \\
1835\end{array}$ & 439 \\
\hline 199 & & $\begin{array}{l}29 \text { December } \\
1835\end{array}$ & 439 \\
\hline
\end{tabular}

7 Stat. 414

7 Stat. 474

7 Stat. 478

7 Stat. 478 1835

Aladdin

Petroleum

Corp. v. State

ex rel. Commis-

sioners of Land

Office (1948)

Vickery v. Yahola

Sand and Gravel

Co. (1932)

Barnett v. Way

(1911)

State ex rel.

May v.

Seneca-Cayuga

Tribe (1985)

Neilson v.

Alberty (1913)

State ex rel.

Martinez v.

Lewis (1993)

200 Okla. 134

Sup. Ct.,

Okla.

158 Okla. $120 \quad$ Sup. Ct.,
Okla.

29 Okla. 780

711 P.2d 77

36 Okla. 490

116 N.M. 194

Sup. Ct.,

Okla.

Sup. Ct., Okla.

Sup. Ct., Okla.

Ct. App., N.M.

Ephraim v.

Garlick (1872)

Strawberry

Valley Cattle

Co. v. Chipman (1896)

Vickery v. Yahola

Sand and Gravel

Co. (1932) 
Aladdin Petroleum

200 Okla. 134

Sup. Ct.,

Corp. v. State

Okla. 1835

$$
1835
$$

29 December

1835

9 December

201 Ottawa;

201

201

201

201

211

222
450

28 March 1836

450

28 March 1836

450

28 March 1836

450

17 September

468

Missouri;

1836

Fox: Missouri

Choctaw;

17 January $1837 \quad 486$

Chickasaw

Kiowa; Kataka;

Tawakoni
28 March 1836 ex rel. Commis-

sioners of Land

7 Stat. 478

Office (1948)

Wildcatt v.

Smith (1984)

Jackson County by

Child Support

Enforcement Agency

v. Swayney (1987)

J \& M Aircraft

Mobile T

Hangars, Inc.

v. Johnson County

Airport

Authority (2004)

People v.

Le Blanc (1974)

People v. Le

Blanc (1976)

In re Wilson (1981) 30 Cal.3d 21

Attorney General v. 127 Mich.

Hermes (1983)

App. 777

In re Petition 224 Ill.

to Adopt T.I.S. (1991) App.3d 475

Hecker v. Bleish 3 S.W.2d

(1927)

1008

Godfrey v. Iowa Land 95 P. 792

and Trust Co. (1908)

State ex rel.

116 N.M. 194

Martinez v.

Lewis (1993) 


29 July 1837

491

29 July 1837

491

29 July 1837

491

223

223

29 July 1837

491

29 September

493

Sioux:

Mdewakanton

Cayuga;

Mohawk:

St. Regis;

Oneida;

Onondaga;

Seneca;

Tuscarora

\section{7}

15 January $1838 \quad 502$
15 January $1838 \quad 502$

15 January $1838 \quad 502$

Stockbridge;

Munsee

3 September

1839

3 September

1839

Wyandot

Seneca

20 May $1842 \quad 537$

20 May $1842 \quad 537$

20 May 1842
17 March $1842 \quad 534$
7 Stat. 536

7 Stat. 536

7 Stat. 536

7 Stat. 536

7 Stat. 538

7 Stat. 550

7 Stat. 550

7 Stat. 550

7 Stat. 580;

11 Stat. 577

7 Stat. 580;

11 Stat. 577

11 Stat. 581

7 Stat. 586

7 Stat. 586

7 Stat. 586

State v. Johnson (1933) 212 Wis. 301

State v. Keezer (1980)

State v. Lowe (1982)

Anderson v. Wisconsin

Department of

Revenue (1992)

State v. Keezer (1980)

Hatch v. Luckman

(1909)

Andrews v. State

(1948)

Snyder v. Wetzler

(1993)

State v. Davids (1994)

State v. Davids (1995)

McAlpin v. Henshaw (1870)

Hatch v. Luckman

(1909)

Snyder v. Wetzler (1993)

New York State

Department of

Taxation and Finance

v. Bramhall (1997)
292 N.W.2d 714

109 Wis.2d 633

169 Wis.2d 255

292 N.W.2d 714

155 A.D. 765

(15.D. 765

Sup. Ct.,

Wis.

Sup. Ct.,

Minn.

Ct. App.,

Wis.

Sup. Ct.,

Wis.

Sup. Ct., Minn.

Sup. Ct., N.Y.

192 Misc. 429

Ct. Cl.,

N.Y.

193 A.D.2d 329

Sup. Ct.,

N.Y.

Ct. App.,

Wis.

Sup. Ct.,

Wis.

Sup. Ct.,

Kan.

Sup. Ct.,

N.Y.

Sup. Ct.,

N.Y.

Sup. Ct., N.Y. 


\begin{tabular}{|c|c|c|c|c|c|c|c|}
\hline 242 & $\begin{array}{l}\text { Chippewa: } \\
\text { Mississippi } \\
\text { Chippewa: } \\
\text { Lake Superior }\end{array}$ & 4 October 1842 & 542 & 7 Stat. 591 & State v. Morrin (1908) & 136 Wis. 552 & $\begin{array}{l}\text { Sup. Ct., } \\
\text { Wis. }\end{array}$ \\
\hline 242 & & 4 October 1842 & 542 & 7 Stat. 591 & $\begin{array}{l}\text { Lemieux v. Agate } \\
\text { Land Co. (1927) }\end{array}$ & 214 N.W. 454 & $\begin{array}{l}\text { Sup. Ct., } \\
\text { Wis. }\end{array}$ \\
\hline 242 & & 4 October 1842 & 542 & 7 Stat. 591 & State v. Johnson (1933) & 212 Wis. 301 & $\begin{array}{l}\text { Sup. Ct., } \\
\text { Wis. }\end{array}$ \\
\hline 242 & & 4 October 1842 & 542 & 7 Stat. 591 & State v. Lowe (1982) & $\begin{array}{l}109 \text { Wis. } \\
\text { 2d } 633\end{array}$ & $\begin{array}{l}\text { Ct. App., } \\
\text { Wis. }\end{array}$ \\
\hline 242 & & 4 October 1842 & 542 & 7 Stat. 591 & $\begin{array}{l}\text { Anderson v. Wisconsin } \\
\text { Department } \\
\text { of Revenue (1992) }\end{array}$ & $\begin{array}{l}169 \text { Wis. } \\
\text { 2d } 255\end{array}$ & $\begin{array}{l}\text { Sup. Ct., } \\
\text { Wis. }\end{array}$ \\
\hline 247 & $\begin{array}{l}\text { Potawatomi; } \\
\text { Chippewa; } \\
\text { Ottawa }\end{array}$ & 5 June 1846 & 557 & 9 Stat. 853 & $\begin{array}{l}\text { State ex rel. Martinez } \\
\text { v. Lewis (1993) }\end{array}$ & 116 N.M. 194 & $\begin{array}{l}\text { Ct. App., } \\
\text { N.M. }\end{array}$ \\
\hline 253 & Menominee & 18 October 1848 & 572 & 9 Stat. 952 & State v. Tucker (1941) & 237 Wis. 310 & $\begin{array}{l}\text { Sup. Ct., } \\
\text { Wis. }\end{array}$ \\
\hline 253 & & 18 October 1848 & 572 & 9 Stat. 952 & $\begin{array}{l}\text { State v. Sanapaw } \\
\text { (1963) }\end{array}$ & $\begin{array}{l}21 \text { Wis. } \\
2 \mathrm{~d} 377\end{array}$ & $\begin{array}{l}\text { Sup. Ct., } \\
\text { Wis. }\end{array}$ \\
\hline 253 & & 18 October 1848 & 572 & 9 Stat. 952 & State v. Webster (1983) & $\begin{array}{l}114 \text { Wis. } \\
\text { 2d } 418\end{array}$ & $\begin{array}{l}\text { Sup. Ct., } \\
\text { Wis. }\end{array}$ \\
\hline 253.1 & Menominee & 12 May 1854 & 626 & 10 Stat. 1064 & State v. Tucker (1941) & 237 Wis. 310 & $\begin{array}{l}\text { Sup. Ct., } \\
\text { Wis. }\end{array}$ \\
\hline 253.1 & & 12 May 1854 & 626 & 10 Stat. 1064 & $\begin{array}{l}\text { State v. Sanapaw } \\
\text { (1963) }\end{array}$ & $\begin{array}{l}21 \text { Wis. } \\
2 \text { d } 377\end{array}$ & $\begin{array}{l}\text { Sup. Ct., } \\
\text { Wis. }\end{array}$ \\
\hline 253.1 & & 12 May 1854 & 626 & 10 Stat. 1064 & $\begin{array}{l}\text { People v. Jondreau } \\
\text { (1971) }\end{array}$ & 384 Mich. 539 & $\begin{array}{l}\text { Sup. Ct., } \\
\text { Mich. }\end{array}$ \\
\hline 253.1 & & 12 May 1854 & 626 & 10 Stat. 1064 & State v. Webster (1983) & $\begin{array}{l}114 \text { Wis. } \\
\text { 2d } 418\end{array}$ & $\begin{array}{l}\text { Sup. Ct., } \\
\text { Wis. }\end{array}$ \\
\hline 254 & Stockbridge & $\begin{array}{l}24 \text { November } \\
1848\end{array}$ & 574 & 9 Stat. 955 & State v. Davids (1995) & $\begin{array}{l}194 \text { Wis. } \\
\text { 2d } 386\end{array}$ & $\begin{array}{l}\text { Sup. Ct., } \\
\text { Wis. }\end{array}$ \\
\hline 255 & Navajo & $\begin{array}{l}9 \text { September } \\
1849\end{array}$ & 583 & 9 Stat. 974 & Begay v. Miller (1950) & 70 Ariz. 380 & $\begin{array}{l}\text { Sup. Ct., } \\
\text { Ariz. }\end{array}$ \\
\hline
\end{tabular}




\begin{tabular}{|c|c|c|c|c|c|c|c|}
\hline 255 & & $\begin{array}{l}9 \text { September } \\
1849\end{array}$ & 583 & 9 Stat. 974 & $\begin{array}{l}\text { State ex rel. Martinez } \\
\text { v. Lewis (1993) }\end{array}$ & 116 N.M. 194 & $\begin{array}{l}\text { Ct. App., } \\
\text { N.M. }\end{array}$ \\
\hline 259 & $\begin{array}{l}\text { Sioux: } \\
\text { Mdewakanton } \\
\text { and Wahpekute }\end{array}$ & 5 August 1851 & 591 & 10 Stat. 954 & $\begin{array}{l}\text { Sharon v. } \\
\text { Wooldrick } \\
\text { (1872) }\end{array}$ & 18 Minn. 354 & $\begin{array}{l}\text { Sup. Ct., } \\
\text { Minn. }\end{array}$ \\
\hline 261 & Apache & 1 July 1852 & 598 & 10 Stat. 979 & $\begin{array}{l}\text { Chino v. Chino } \\
\text { (1977) }\end{array}$ & 90 N.M. 203 & $\begin{array}{l}\text { Sup. Ct., } \\
\text { N.M. }\end{array}$ \\
\hline 261 & & 1 July 1852 & 598 & 10 Stat. 979 & $\begin{array}{l}\text { United States } \\
\text { v. Superior } \\
\text { Court (1985) }\end{array}$ & 144 Ariz. 265 & $\begin{array}{l}\text { Sup. Ct., } \\
\text { Ariz. }\end{array}$ \\
\hline 261 & & 1 July 1852 & 598 & 10 Stat. 979 & $\begin{array}{l}\text { State ex rel. } \\
\text { Martinez v. } \\
\text { Lewis (1993) }\end{array}$ & 116 N.M. 194 & $\begin{array}{l}\text { Ct. App., } \\
\text { N.M. }\end{array}$ \\
\hline 266 & Omaha & 16 March 1854 & 611 & 10 Stat. 1043 & $\begin{array}{l}\text { State v. } \\
\text { Nimrod (1912) }\end{array}$ & 30 S.D. 239 & $\begin{array}{l}\text { Sup. Ct., } \\
\text { S.D. }\end{array}$ \\
\hline 266 & & 16 March 1854 & 611 & 10 Stat. 1043 & $\begin{array}{l}\text { Snohomish } \\
\text { County v. } \\
\text { Seattle } \\
\text { Disposal Co. } \\
\text { (1967) }\end{array}$ & 70 Wash.2d 668 & $\begin{array}{l}\text { Sup. Ct., } \\
\text { Wash. }\end{array}$ \\
\hline 268 & Shawnee & 10 May 1854 & 618 & 10 Stat. 1053 & $\begin{array}{l}\text { Blue-Jacket } \\
\text { v. Commis- } \\
\text { sioners of } \\
\text { Johnson } \\
\text { County (1865) }\end{array}$ & 3 Kan. 299 & $\begin{array}{l}\text { Sup. Ct., } \\
\text { Kan. }\end{array}$ \\
\hline 268 & & 10 May 1854 & 618 & 10 Stat. 1053 & $\begin{array}{l}\text { McAlpin v. } \\
\text { Henshaw (1870) }\end{array}$ & 6 Kan. 176 & $\begin{array}{l}\text { Sup. Ct., } \\
\text { Kan. }\end{array}$ \\
\hline 268 & & 10 May 1854 & 618 & 10 Stat. 1053 & $\begin{array}{l}\text { Hale v. Wilder } \\
\text { (1871) }\end{array}$ & 8 Kan. 545 & $\begin{array}{l}\text { Sup. Ct., } \\
\text { Kan. }\end{array}$ \\
\hline 268 & & 10 May 1854 & 618 & 10 Stat. 1053 & $\begin{array}{l}\text { Brown v. Steele } \\
(1880)\end{array}$ & 23 Kan. 672 & $\begin{array}{l}\text { Sup. Ct., } \\
\text { Kan. }\end{array}$ \\
\hline 268 & & 10 May 1854 & 618 & 10 Stat. 1053 & $\begin{array}{l}\text { State v. O'Laughlin } \\
(1882)\end{array}$ & 29 Kan. 20 & $\begin{array}{l}\text { Sup. Ct., } \\
\text { Kan. }\end{array}$ \\
\hline 268 & & 10 May 1854 & 618 & 10 Stat. 1053 & $\begin{array}{l}\text { O'Brien v. Bugbee } \\
(1891)\end{array}$ & 46 Kan. 1 & $\begin{array}{l}\text { Sup. Ct., } \\
\text { Kan. }\end{array}$ \\
\hline
\end{tabular}




\begin{tabular}{|c|c|c|c|c|c|c|c|}
\hline 268 & & 10 May 1854 & 618 & 10 Stat. 1053 & $\begin{array}{l}\text { Hannon v. Taylor } \\
\text { (1896) }\end{array}$ & 57 Kan. 1 & $\begin{array}{l}\text { Sup. Ct., } \\
\text { Kan. }\end{array}$ \\
\hline 269 & Menominee & 12 May 1854 & 626 & 10 Stat. 1064 & State v. Tucker (1941) & 237 Wis. 310 & $\begin{array}{l}\text { Sup. Ct., } \\
\text { Wis. }\end{array}$ \\
\hline 269 & & 12 May 1854 & 626 & 10 Stat. 1064 & $\begin{array}{l}\text { State v. Sanapaw } \\
\text { (1963) }\end{array}$ & 21 Wis. $2 \mathrm{~d} 377$ & $\begin{array}{l}\text { Sup. Ct., } \\
\text { Wis. }\end{array}$ \\
\hline 269 & & 12 May 1854 & 626 & 10 Stat. 1064 & $\begin{array}{l}\text { People v. Jondreau } \\
\text { (1971) }\end{array}$ & 384 Mich. 539 & $\begin{array}{l}\text { Sup. Ct., } \\
\text { Mich. }\end{array}$ \\
\hline 269 & & 12 May 1854 & 626 & 10 Stat. 1064 & State v. Webster (1983) & 114 Wis.2d 418 & $\begin{array}{l}\text { Sup. Ct., } \\
\text { Wis. }\end{array}$ \\
\hline 274 & Miami & 5 June 1854 & 641 & 10 Stat. 1093 & $\begin{array}{l}\text { Miami County Com'rs } \\
\text { v. Wan-zop-pe-che } \\
\text { (1865) }\end{array}$ & 3 Kan. 364 & $\begin{array}{l}\text { Sup. Ct., } \\
\text { Kan. }\end{array}$ \\
\hline 275 & $\begin{array}{l}\text { Chippewa: } \\
\text { Mississippi } \\
\text { Chippewa: } \\
\text { Lake Superior }\end{array}$ & $\begin{array}{l}30 \text { September } \\
1854\end{array}$ & 648 & 10 Stat. 1109 & State v. Morrin (1908) & 136 Wis. 552 & $\begin{array}{l}\text { Sup. Ct., } \\
\text { Wis. }\end{array}$ \\
\hline 275 & & $\begin{array}{l}30 \text { September } \\
1854\end{array}$ & 648 & 10 Stat. 1109 & $\begin{array}{l}\text { Laveirge v. Davis } \\
\text { (1926) }\end{array}$ & 206 N.W. 939 & $\begin{array}{l}\text { Sup. Ct., } \\
\text { Minn. }\end{array}$ \\
\hline 275 & & $\begin{array}{l}30 \text { September } \\
1854\end{array}$ & 648 & 10 Stat. 1109 & $\begin{array}{l}\text { McGeehan v. Ashland } \\
\text { County (1927) }\end{array}$ & 192 Wis. 177 & $\begin{array}{l}\text { Sup. Ct., } \\
\text { Wis. }\end{array}$ \\
\hline 275 & & $\begin{array}{l}30 \text { September } \\
1854\end{array}$ & 648 & 10 Stat. 1109 & $\begin{array}{l}\text { Lemieux v. Agate Land } \\
\text { Co. (1927) }\end{array}$ & 214 N.W. 454 & $\begin{array}{l}\text { Sup. Ct., } \\
\text { Wis. }\end{array}$ \\
\hline 275 & & $\begin{array}{l}30 \text { September } \\
1854\end{array}$ & 648 & 10 Stat. 1109 & State v. Johnson (1933) & 212 Wis. 301 & $\begin{array}{l}\text { Sup. Ct., } \\
\text { Wis. }\end{array}$ \\
\hline 275 & & $\begin{array}{l}30 \text { September } \\
1854\end{array}$ & 648 & 10 Stat. 1109 & State v. Gurnoe (1972) & 53 Wis.2d 390 & $\begin{array}{l}\text { Sup. Ct., } \\
\text { Wis. }\end{array}$ \\
\hline 275 & & $\begin{array}{l}30 \text { September } \\
1854\end{array}$ & 648 & 10 Stat. 1109 & $\begin{array}{l}\text { People v. Jondreau } \\
\text { (1971) }\end{array}$ & 384 Mich. 539 & $\begin{array}{l}\text { Sup. Ct., } \\
\text { Mich. }\end{array}$ \\
\hline 275 & & $\begin{array}{l}30 \text { September } \\
1854\end{array}$ & 648 & 10 Stat. 1109 & $\begin{array}{l}\text { State v. Whitebird } \\
\text { (1982) }\end{array}$ & 110 Wis.2d 250 & $\begin{array}{l}\text { Ct. App., } \\
\text { Wis. }\end{array}$ \\
\hline 275 & & $\begin{array}{l}30 \text { September } \\
1854\end{array}$ & 648 & 10 Stat. 1109 & $\begin{array}{l}\text { State v. Lemieux } \\
\text { (1983) }\end{array}$ & 110 Wis.2d 158 & $\begin{array}{l}\text { Sup. Ct., } \\
\text { Wis. }\end{array}$ \\
\hline 275 & & $\begin{array}{l}30 \text { September } \\
1854\end{array}$ & 648 & 10 Stat. 1109 & $\begin{array}{l}\text { State v. Newago } \\
\text { (1986) }\end{array}$ & 134 Wis.2d 420 & $\begin{array}{l}\text { Ct. App., } \\
\text { Wis. }\end{array}$ \\
\hline
\end{tabular}




\begin{tabular}{|c|c|c|c|c|c|c|c|}
\hline 275 & & $\begin{array}{l}30 \text { September } \\
1854\end{array}$ & 648 & 10 Stat. 1109 & $\begin{array}{l}\text { Anderson v. Wisconsin } \\
\text { Department of } \\
\text { Revenue (1992) }\end{array}$ & 169 Wis.2d 255 & $\begin{array}{l}\text { Sup. Ct., } \\
\text { Wis. }\end{array}$ \\
\hline 276 & $\begin{array}{l}\text { Choctaw; } \\
\text { Chickasaw }\end{array}$ & $\begin{array}{l}4 \text { November } \\
1854\end{array}$ & 652 & 10 Stat. 1116 & $\begin{array}{l}\text { Sharp v. Lancaster } \\
\text { (1909) }\end{array}$ & 23 Okla. 349 & $\begin{array}{l}\text { Sup. Ct., } \\
\text { Okla. }\end{array}$ \\
\hline 281 & $\begin{array}{l}\text { Nisqually; } \\
\text { Puyallup; } \\
\text { Steilacoom; } \\
\text { Squaxin; } \\
\text { Homamish; } \\
\text { Stehchass; } \\
\text { Tapeeksin; } \\
\text { Squiaitl; } \\
\text { Sahewamish }\end{array}$ & $\begin{array}{l}26 \text { December } \\
1854\end{array}$ & 661 & 10 Stat. 1132 & $\begin{array}{l}\text { Page v. Pierce County } \\
\text { (1901) }\end{array}$ & 25 Wash. 6 & $\begin{array}{l}\text { Sup. Ct., } \\
\text { Wash. }\end{array}$ \\
\hline 281 & & $\begin{array}{l}26 \text { December } \\
1854\end{array}$ & 661 & 10 Stat. 1132 & $\begin{array}{l}\text { State v. Satiacum } \\
\text { (1957) }\end{array}$ & 50 Wash.2d 513 & $\begin{array}{l}\text { Sup. Ct., } \\
\text { Wash. }\end{array}$ \\
\hline 281 & & $\begin{array}{l}26 \text { December } \\
1854\end{array}$ & 661 & 10 Stat. 1132 & $\begin{array}{l}\text { Department of Game } \\
\text { v. Puyallup Tribe, Inc. } \\
\text { (1967) }\end{array}$ & 70 Wash.2d 245 & $\begin{array}{l}\text { Sup. Ct., } \\
\text { Wash. }\end{array}$ \\
\hline 281 & & $\begin{array}{l}26 \text { December } \\
1854\end{array}$ & 661 & 10 Stat. 1132 & State v. Tinno (1972) & 94 Idaho 759 & $\begin{array}{l}\text { Sup. Ct., } \\
\text { Idaho }\end{array}$ \\
\hline 281 & & $\begin{array}{l}26 \text { December } \\
1854\end{array}$ & 661 & 10 Stat. 1132 & $\begin{array}{l}\text { Department of Game } \\
\text { v. Puyallup Tribe, Inc. } \\
\text { (1972) }\end{array}$ & 80 Wash.2d 561 & $\begin{array}{l}\text { Sup. Ct., } \\
\text { Wash. }\end{array}$ \\
\hline 281 & & $\begin{array}{l}26 \text { December } \\
1854\end{array}$ & 661 & 10 Stat. 1132 & $\begin{array}{l}\text { Department of Game } \\
\text { v. Puyallup Tribe, Inc. } \\
\text { (1976) }\end{array}$ & 86 Wash.2d 664 & $\begin{array}{l}\text { Sup. Ct., } \\
\text { Wash. }\end{array}$ \\
\hline 281 & & $\begin{array}{l}26 \text { December } \\
1854\end{array}$ & 661 & 10 Stat. 1132 & $\begin{array}{l}\text { Washington State } \\
\text { Commercial Passenger } \\
\text { Fishing Vessel Assoc. } \\
\text { v. Tollefson (1977) }\end{array}$ & 89 Wash.2d 276 & $\begin{array}{l}\text { Sup. Ct., } \\
\text { Wash. }\end{array}$ \\
\hline 281 & & $\begin{array}{l}26 \text { December } \\
1854\end{array}$ & 661 & 10 Stat. 1132 & $\begin{array}{l}\text { Puget Sound } \\
\text { Gillnetters Assoc. } \\
\text { v. Moos (1977) }\end{array}$ & 88 Wash.2d 677 & $\begin{array}{l}\text { Sup. Ct., } \\
\text { Wash. }\end{array}$ \\
\hline
\end{tabular}


Puget Sound Gillnetters Assoc. v. Moos

(1979)

Staktalijamish;

Mesekwegwils;
281

281

281

283

Duwamish;

Suquamish;

Stkehlmish;

Sammamish;

Smulkamish;

Skopamish;

Stkamish;

Snoqualmie;

Skykomish;

Kwehtlamamish;

Stillaguamish;

Snohomish;

Skagit;

Kikiallus;

Swinomish;

Squinamish;

Sauk-Suiattle;

Nuwhaha;

Nookachamps;

Chobaabish

26 December 661

1854

26 December 661

1854

26 December 66

1854

22 January $1855 \quad 669$

283

22 January 1855
669
10 Stat. 1132

10 Stat. 1132

(1983)

State v. Stritmatter

(1984)

10 Stat. 1132

12 Stat. 927 State

\section{Jackson v. Thompson}

(1905)
92 Wash.2d 939

36 Wash.

App. 615

102 Wash.2d 516

132 Wash.2d 333

38 Wash. 282
Sup. Ct.,

Wash.

Ct. App.,

Wash.

Sup. Ct.,

Wash.

Sup. Ct.,

Wash.

Sup. Ct.,

Wash. 


\begin{tabular}{|c|c|c|c|c|c|c|}
\hline 283 & 22 January 1855 & 669 & 12 Stat. 927 & State v. McCoy (1963) & 63 Wash.2d 421 & $\begin{array}{l}\text { Sup. Ct., } \\
\text { Wash. }\end{array}$ \\
\hline 283 & 22 January 1855 & 669 & 12 Stat. 927 & $\begin{array}{l}\text { Snohomish County } \\
\text { v. Seattle Disposal } \\
\text { Co. (1967) }\end{array}$ & 70 Wash.2d 668 & $\begin{array}{l}\text { Sup. Ct., } \\
\text { Wash. }\end{array}$ \\
\hline 283 & 22 January 1855 & 669 & 12 Stat. 927 & State v. Moses (1967) & 70 Wash.2d 282 & $\begin{array}{l}\text { Sup. Ct., } \\
\text { Wash. }\end{array}$ \\
\hline 283 & 22 January 1855 & 669 & 12 Stat. 927 & $\begin{array}{l}\text { Department of Game } \\
\text { v. Puyallup Tribe, Inc. } \\
\text { (1967) }\end{array}$ & 70 Wash.2d 245 & $\begin{array}{l}\text { Sup. Ct., } \\
\text { Wash. }\end{array}$ \\
\hline 283 & 22 January 1855 & 669 & 12 Stat. 927 & State v. Moses (1971) & 79 Wash.2d 104 & $\begin{array}{l}\text { Sup. Ct., } \\
\text { Wash. }\end{array}$ \\
\hline 283 & 22 January 1855 & 669 & 12 Stat. 927 & $\begin{array}{l}\text { Department of Game } \\
\text { v. Puyallup Tribe, Inc. } \\
\text { (1972) }\end{array}$ & 80 Wash.2d 561 & $\begin{array}{l}\text { Sup. Ct., } \\
\text { Wash. }\end{array}$ \\
\hline 283 & 22 January 1855 & 669 & 12 Stat. 927 & $\begin{array}{l}\text { Chief Seattle } \\
\text { Properties, Inc. v. } \\
\text { Kitsap County (1975) }\end{array}$ & 86 Wash.2d 7 & $\begin{array}{l}\text { Sup. Ct., } \\
\text { Wash. }\end{array}$ \\
\hline 283 & 22 January 1855 & 669 & 12 Stat. 927 & $\begin{array}{l}\text { Department of Game v. } \\
\text { Puyallup Tribe, Inc. } \\
\text { (1976) }\end{array}$ & 86 Wash.2d 664 & $\begin{array}{l}\text { Sup. Ct., } \\
\text { Wash. }\end{array}$ \\
\hline 283 & 22 January 1855 & 669 & 12 Stat. 927 & $\begin{array}{l}\text { Puget Sound } \\
\text { Gillnetters Assoc. } \\
\text { v. Moos (1979) }\end{array}$ & 92 Wash.2d 939 & $\begin{array}{l}\text { Sup. Ct., } \\
\text { Wash. }\end{array}$ \\
\hline 283 & 22 January 1855 & 669 & 12 Stat. 927 & $\begin{array}{l}\text { State v. Courville } \\
\text { (1983) }\end{array}$ & 36 Wash. App. 615 & $\begin{array}{l}\text { Ct. App., } \\
\text { Wash. }\end{array}$ \\
\hline 283 & 22 January 1855 & 669 & 12 Stat. 927 & $\begin{array}{l}\text { State ex rel. Martinez } \\
\text { v. Lewis (1993) }\end{array}$ & 116 N.M. 194 & $\begin{array}{l}\text { Ct. App., } \\
\text { N.M. }\end{array}$ \\
\hline 283 & 22 January 1855 & 669 & 12 Stat. 927 & $\begin{array}{l}\text { State v. Schmuck } \\
\text { (1993) }\end{array}$ & 121 Wash.2d 373 & $\begin{array}{l}\text { Sup. Ct., } \\
\text { Wash. }\end{array}$ \\
\hline 283 & 22 January 1855 & 669 & 12 Stat. 927 & $\begin{array}{l}\text { State v. Buchanan } \\
\text { (1997) }\end{array}$ & 87 Wash. App. 189 & $\begin{array}{l}\text { Ct. App., } \\
\text { Wash. }\end{array}$ \\
\hline 283 & 22 January 1855 & 669 & 12 Stat. 927 & $\begin{array}{l}\text { State v. Buchanan } \\
\text { (1999) }\end{array}$ & 138 Wash.2d 186 & $\begin{array}{l}\text { Sup. Ct., } \\
\text { Wash. }\end{array}$ \\
\hline 283 & 22 January 1855 & 669 & 12 Stat. 927 & $\begin{array}{l}\text { State v. Moses } \\
(2001)\end{array}$ & $\begin{array}{l}104 \text { Wash. } \\
\text { App. } 153\end{array}$ & $\begin{array}{l}\text { Ct. App., } \\
\text { Wash. }\end{array}$ \\
\hline
\end{tabular}


Clallam;

Skokomish;

Chemakum

26 January 1855

Wyandot

31 January $1855 \quad 677$

31 January $1855 \quad 677$

31 January $1855 \quad 677$

31 January $1855 \quad 677$

Makah

31 January $1855 \quad 682$

31 January $1855 \quad 682$

31 January $1855 \quad 682$

31 January $1855 \quad 682$

31 January $1855 \quad 682$
12 Stat. 927

12 Stat. 933

12 Stat. 933

12 Stat. 933

12 Stat. 933

10 Stat. 1159

10 Stat. 1159

10 Stat. 1159

10 Stat. 1159

12 Stat. 939

12 Stat. 939

12 Stat. 939

12 Stat. 939

12 Stat. 939
Landau v. San Juan

County (2001)

Department of Game v.

Puyallup Tribe, Inc.

(1972)

Department of Game v. 86 Wash.2d 664

Puyallup Tribe, Inc.

(1976)

Puget Sound

Gillnetters Assoc. v.

Moos (1979)

State v. Miller (1984) 102 Wash.2d 678

Summers v. Spybuck 1 Kan. 394

(1863)

Walker v. Armstrong 2 Kan. 198

(1863)

Frederick v. Gray 12 Kan. 518

(1874)

Rider v. Helms (1915) 48 Okla. 610

Neah Bay Fish Co. v. 3 Wash.2d 570

Krummel (1940)

Department of Game v. 70 Wash.2d 245

Puyallup Tribe, Inc.

(1967)

Makah Indian Tribe v. 73 Wash.2d 677

Clallam County (1968)

Makah Indian Tribe v. 76 Wash.2d 485

State (1969)

Department of Game v.

Puyallup Tribe, Inc.

(1972)
Ct. App., Wash.

Sup. Ct., Wash.

Sup. Ct., Wash.

Sup. Ct., Wash.

Sup. Ct., Wash.

Sup. Ct.,

Kan.

Sup. Ct.,

Kan.

Sup. Ct.,

Kan.

Sup. Ct.,

Okla.

Sup. Ct.,

Wash.

Sup. Ct.,

Wash.

Sup. Ct., Wash.

Sup. Ct.,

Wash.

Sup. Ct.,

Wash. 


\begin{tabular}{|c|c|c|c|c|c|c|c|}
\hline 286 & & 31 January 1855 & 682 & 12 Stat. 939 & $\begin{array}{l}\text { Puget Sound Gillnet- } \\
\text { ters Assoc. v. Moos } \\
\text { (1979) }\end{array}$ & 92 Wash.2d 939 & $\begin{array}{l}\text { Sup. Ct., } \\
\text { Wash. }\end{array}$ \\
\hline 286 & & 31 January 1855 & 682 & 12 Stat. 939 & $\begin{array}{l}\text { State v. Buchanan } \\
\text { (1999) }\end{array}$ & 138 Wash.2d 186 & $\begin{array}{l}\text { Sup. Ct., } \\
\text { Wash. }\end{array}$ \\
\hline 287 & $\begin{array}{l}\text { Chippewa: } \\
\text { Mississippi, } \\
\text { Pillager and } \\
\text { Lake } \\
\text { Winnibigoshish }\end{array}$ & $\begin{array}{l}22 \text { February } \\
1855\end{array}$ & 685 & 10 Stat. 1165 & White v. Wright (1901) & 83 Minn. 222 & $\begin{array}{l}\text { Sup. Ct., } \\
\text { Minn. }\end{array}$ \\
\hline 287 & & $\begin{array}{l}22 \text { February } \\
1855\end{array}$ & 685 & 10 Stat. 1165 & $\begin{array}{l}\text { Bem-way-bin-ness v. } \\
\text { Eshelby (1902) }\end{array}$ & 87 Minn. 108 & $\begin{array}{l}\text { Sup. Ct., } \\
\text { Minn. }\end{array}$ \\
\hline 287 & & $\begin{array}{l}22 \text { February } \\
1855\end{array}$ & 685 & 10 Stat. 1165 & $\begin{array}{l}\text { Nicholson v. Congdon } \\
\text { (1905) }\end{array}$ & 95 Minn. 188 & $\begin{array}{l}\text { Sup. Ct., } \\
\text { Minn. }\end{array}$ \\
\hline 287 & & $\begin{array}{l}22 \text { February } \\
1855\end{array}$ & 685 & 10 Stat. 1165 & $\begin{array}{l}\text { Vachon v. Nichols- } \\
\text { Chisholm Lumber Co. } \\
\text { (1914) }\end{array}$ & 126 Minn. 303 & $\begin{array}{l}\text { Sup. Ct., } \\
\text { Minn. }\end{array}$ \\
\hline 287 & & $\begin{array}{l}22 \text { February } \\
1855\end{array}$ & 685 & 10 Stat. 1165 & Kipp v. Love (1915) & 151 N.W. 201 & $\begin{array}{l}\text { Sup. Ct., } \\
\text { Minn. }\end{array}$ \\
\hline 287 & & $\begin{array}{l}22 \text { February } \\
1855\end{array}$ & 685 & 10 Stat. 1165 & $\begin{array}{l}\text { Minneapolis Brewing } \\
\text { Co. v. Village of } \\
\text { Bagley (1919) }\end{array}$ & 142 Minn. 16 & $\begin{array}{l}\text { Sup. Ct., } \\
\text { Minn. }\end{array}$ \\
\hline 287 & & $\begin{array}{l}22 \text { February } \\
1855\end{array}$ & 685 & 10 Stat. 1165 & $\begin{array}{l}\text { Courtright v. City of } \\
\text { Detroit (1931) }\end{array}$ & 183 N.W. 346 & $\begin{array}{l}\text { Sup. Ct., } \\
\text { Minn. }\end{array}$ \\
\hline 287 & & $\begin{array}{l}22 \text { February } \\
1855\end{array}$ & 685 & 10 Stat. 1165 & State v. Cloud (1930) & 179 Minn. 180 & $\begin{array}{l}\text { Sup. Ct., } \\
\text { Minn. }\end{array}$ \\
\hline 287 & & $\begin{array}{l}22 \text { February } \\
1855\end{array}$ & 685 & 10 Stat. 1165 & State v. Bush (1935) & 195 Minn. 413 & $\begin{array}{l}\text { Sup. Ct., } \\
\text { Minn. }\end{array}$ \\
\hline 287 & & $\begin{array}{l}22 \text { February } \\
1855\end{array}$ & 685 & 10 Stat. 1165 & State v. Jackson (1944) & 218 Minn. 429 & $\begin{array}{l}\text { Sup. Ct., } \\
\text { Minn. }\end{array}$ \\
\hline 287 & & $\begin{array}{l}22 \text { February } \\
1855\end{array}$ & 685 & 10 Stat. 1165 & State v. Forge (1977) & 262 N.W.2d 341 & $\begin{array}{l}\text { Sup. Ct., } \\
\text { Minn. }\end{array}$ \\
\hline 287 & & $\begin{array}{l}22 \text { February } \\
1855\end{array}$ & 685 & 10 Stat. 1165 & State v. Clark (1979) & 282 N.W.2d 902 & $\begin{array}{l}\text { Sup. Ct., } \\
\text { Minn. }\end{array}$ \\
\hline 287 & & $\begin{array}{l}22 \text { February } \\
1855\end{array}$ & 685 & 10 Stat. 1165 & State v. Keezer (1980) & 292 N.W.2d 714 & $\begin{array}{l}\text { Sup. Ct., } \\
\text { Minn. }\end{array}$ \\
\hline
\end{tabular}

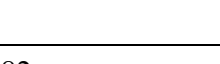




\begin{tabular}{|c|c|c|c|c|c|c|c|}
\hline 289 & $\begin{array}{l}\text { Walla Walla; } \\
\text { Cayuse; } \\
\text { Umatilla }\end{array}$ & 9 June 1855 & 694 & 12 Stat. 945 & $\begin{array}{l}\text { Mosgrove v. Harper } \\
\text { (1898) }\end{array}$ & 33 Ore. 252 & $\begin{array}{l}\text { Sup. Ct., } \\
\text { Or. }\end{array}$ \\
\hline 289 & & 9 June 1855 & 694 & 12 Stat. 945 & $\begin{array}{l}\text { Kalyton v. Kalyton } \\
\text { (1903) }\end{array}$ & 45 Or. 116 & $\begin{array}{l}\text { Sup. Ct., } \\
\text { Or. }\end{array}$ \\
\hline 289 & & 9 June 1855 & 694 & 12 Stat. 945 & $\begin{array}{l}\text { Byers v. We-wa-ne } \\
\text { (1917) }\end{array}$ & 86 Ore. 617 & $\begin{array}{l}\text { Sup. Ct., } \\
\text { Or. }\end{array}$ \\
\hline 289 & & 9 June 1855 & 694 & 12 Stat. 945 & $\begin{array}{l}\text { Merrill v. Bishop } \\
\text { (1955) }\end{array}$ & 74 Wyo. 298 & $\begin{array}{l}\text { Sup. Ct., } \\
\text { Wyo. }\end{array}$ \\
\hline 289 & & 9 June 1855 & 694 & 12 Stat. 945 & $\begin{array}{l}\text { Department of Game v. } \\
\text { Puyallup Tribe, Inc. } \\
\text { (1972) }\end{array}$ & 80 Wash.2d 561 & $\begin{array}{l}\text { Sup. Ct., } \\
\text { Wash. }\end{array}$ \\
\hline 289 & & 9 June 1855 & 694 & 12 Stat. 945 & State v. Coffee (1976) & 97 Idaho 905 & $\begin{array}{l}\text { Sup. Ct., } \\
\text { Idaho }\end{array}$ \\
\hline 289 & & 9 June 1855 & 694 & 12 Stat. 945 & $\begin{array}{l}\text { Department of Game v. } \\
\text { Puyallup Tribe, Inc. } \\
\text { (1976) }\end{array}$ & 86 Wash.2d 664 & $\begin{array}{l}\text { Sup. Ct., } \\
\text { Wash. }\end{array}$ \\
\hline 289 & & 9 June 1855 & 694 & 12 Stat. 945 & $\begin{array}{l}\text { Roman Catholic } \\
\text { Bishop v. Department } \\
\text { of Revenue (1981) }\end{array}$ & 9 Or. Tax 122 & $\begin{array}{l}\text { Tax Ct., } \\
\text { Or. }\end{array}$ \\
\hline 289 & & 9 June 1855 & 694 & 12 Stat. 945 & $\begin{array}{l}\text { State v. Buchanan } \\
\text { (1999) }\end{array}$ & 138 Wash.2d 186 & $\begin{array}{l}\text { Sup. Ct., } \\
\text { Wash. }\end{array}$ \\
\hline 290 & $\begin{array}{l}\text { Yakima; } \\
\text { Palouse; } \\
\text { Pisquouse; } \\
\text { Wenatchee; } \\
\text { Klikitat; } \\
\text { Klinquit; } \\
\text { Kowwassayee; } \\
\text { Liaywas; Skin; } \\
\text { Wishram; } \\
\text { Shyiks; } \\
\text { Ochechotes; } \\
\text { Kahmiltpah; } \\
\text { Seapcat }\end{array}$ & 9 June 1855 & 698 & 12 Stat. 951 & Hough v. Taylor (1920) & 110 Wash. 361 & $\begin{array}{l}\text { Sup. Ct., } \\
\text { Wash. }\end{array}$ \\
\hline
\end{tabular}




\begin{tabular}{|c|c|c|c|c|c|c|}
\hline 290 & 9 June 1855 & 698 & 12 Stat. 951 & $\begin{array}{l}\text { State v. Wallahee } \\
\text { (1927) }\end{array}$ & 143 Wash. 117 & $\begin{array}{l}\text { Sup. Ct., } \\
\text { Wash. }\end{array}$ \\
\hline 290 & 9 June 1855 & 698 & 12 Stat. 951 & State v. Tulee (1941) & 7 Wash.2d 124 & $\begin{array}{l}\text { Sup. Ct., } \\
\text { Wash. }\end{array}$ \\
\hline 290 & 9 June 1855 & 698 & 12 Stat. 951 & $\begin{array}{l}\text { Seufert Bros. Co. v. } \\
\text { Hoptowit (1951) }\end{array}$ & 193 Or. 317 & $\begin{array}{l}\text { Sup. Ct., } \\
\text { Or. }\end{array}$ \\
\hline 290 & 9 June 1855 & 698 & 12 Stat. 951 & $\begin{array}{l}\text { State v. McClure } \\
\text { (1954) }\end{array}$ & 127 Mont. 534 & $\begin{array}{l}\text { Sup. Ct., } \\
\text { Mont. }\end{array}$ \\
\hline 290 & 9 June 1855 & 698 & 12 Stat. 951 & $\begin{array}{l}\text { State ex rel. Clark v. } \\
\text { Hogan }(1956)\end{array}$ & 49 Wash.2d 457 & $\begin{array}{l}\text { Sup. Ct., } \\
\text { Wash. }\end{array}$ \\
\hline 290 & 9 June 1855 & 698 & 12 Stat. 951 & $\begin{array}{l}\text { State v. Satiacum } \\
\text { (1957) }\end{array}$ & 50 Wash.2d 513 & $\begin{array}{l}\text { Sup. Ct., } \\
\text { Wash. }\end{array}$ \\
\hline 290 & 9 June 1855 & 698 & 12 Stat. 951 & In re Colwash (1960) & 57 Wash.2d 196 & $\begin{array}{l}\text { Sup. Ct., } \\
\text { Wash. }\end{array}$ \\
\hline 290 & 9 June 1855 & 698 & 12 Stat. 951 & State v. James (1967) & 72 Wash.2d 746 & $\begin{array}{l}\text { Sup. Ct., } \\
\text { Wash. }\end{array}$ \\
\hline 290 & 9 June 1855 & 698 & 12 Stat. 951 & $\begin{array}{l}\text { People v. Jondreau } \\
\text { (1971) }\end{array}$ & 384 Mich. 539 & $\begin{array}{l}\text { Sup. Ct., } \\
\text { Mich. }\end{array}$ \\
\hline 290 & 9 June 1855 & 698 & 12 Stat. 951 & $\begin{array}{l}\text { Department of Game v. } \\
\text { Puyallup Tribe, Inc. } \\
\text { (1972) }\end{array}$ & 80 Wash.2d 561 & $\begin{array}{l}\text { Sup. Ct., } \\
\text { Wash. }\end{array}$ \\
\hline 290 & 9 June 1855 & 698 & 12 Stat. 951 & $\begin{array}{l}\text { State v. Chambers } \\
\text { (1973) }\end{array}$ & 81 Wash.2d 929 & $\begin{array}{l}\text { Sup. Ct., } \\
\text { Wash. }\end{array}$ \\
\hline 290 & 9 June 1855 & 698 & 12 Stat. 951 & State v. Coffee (1976) & 97 Idaho 905 & $\begin{array}{l}\text { Sup. Ct., } \\
\text { Idaho }\end{array}$ \\
\hline 290 & 9 June 1855 & 698 & 12 Stat. 951 & $\begin{array}{l}\text { Department of Game v. } \\
\text { Puyallup Tribe, Inc. } \\
\text { (1976) }\end{array}$ & 86 Wash.2d 664 & $\begin{array}{l}\text { Sup. Ct., } \\
\text { Wash. }\end{array}$ \\
\hline 290 & 9 June 1855 & 698 & 12 Stat. 951 & $\begin{array}{l}\text { Puget Sound } \\
\text { Gillnetters Assoc. v. } \\
\text { Moos (1979) }\end{array}$ & 92 Wash.2d 939 & $\begin{array}{l}\text { Sup. Ct., } \\
\text { Wash. }\end{array}$ \\
\hline 290 & 9 June 1855 & 698 & 12 Stat. 951 & State v. Smith (1981) & 51 Ore. App. 223 & $\begin{array}{l}\text { Ct. App., } \\
\text { Or. }\end{array}$ \\
\hline 290 & 9 June 1855 & 698 & 12 Stat. 951 & $\begin{array}{l}\text { Wildcatt v. Smith } \\
\text { (1984) }\end{array}$ & 311 N.C. 397 & $\begin{array}{l}\text { Ct. App., } \\
\text { N.C. }\end{array}$ \\
\hline
\end{tabular}


Nez Perce

11 June $1855 \quad 702$

11 June $1855 \quad 702$

11 June 1855

11 June $1855 \quad 702$

11 June $1855 \quad 702$

11 June $1855 \quad 702$

11 June 1855

11 June 1855
12 Stat. 951

State v. Jim (1986)

State v. Sohappy

(1988)

In re Application of

Otter Tail Power Co.

(1990)

Yakima River Drainage

Basin v. Yakima

Reservation Irrigation

District (1993)

12 Stat. 951

Columbia Gorge

Audobon Society v.

Klickitat County

(1999)

12 Stat. 95

12 Stat. 957

12 Stat. 957

12 Stat. 957

12 Stat. 957

12 Stat. 957

12 Stat. 957

2 Stat. 957

12 Stat. 957

State v. Buchanan

(1999)

Neah Bay Fish Co. v.

Krummel (1940)

State v. McConville

(1943)

(1956)

(1971)

Puyallup Tribe, Inc.

(1972)

State v. Buchanan
Surface Waters of the

81 Ore. App. 177

110 Wash.2d 907

451 N.W.2d 95

121 Wash.2d 257

State v. Arthur (1953) 74 Idaho 251

State v. Powaukee $\quad 78$ Idaho 257

People v. Jondreau 384 Mich. 539

Department of Game v. $\quad 80$ Wash 2d 561

State v. Coffee (1976) 97 Idaho 905

138 Wash.2d 186
Ct. App., Or.

Sup. Ct., Wash.

Sup. Ct., N.D.

Sup. Ct., Wash.

Ct. App., Wash.

Sup. Ct., Wash.

Sup. Ct., Wash.

Sup. Ct., Idaho

Sup. Ct., Idaho

Sup. Ct., Idaho

Sup. Ct., Mich.

Sup. Ct., Wash.

Sup. Ct., Idaho Sup. Ct., Wash. 


\begin{tabular}{|c|c|c|c|c|c|c|c|}
\hline 291.1 & Nez Perce & 9 June 1863 & 843 & 14 Stat. 647 & $\begin{array}{l}\text { State v. McConville } \\
\text { (1943) }\end{array}$ & 65 Idaho 46 & $\begin{array}{l}\text { Sup. Ct., } \\
\text { Idaho }\end{array}$ \\
\hline 291.1 & & 9 June 1863 & 843 & 14 Stat. 647 & State v. Arthur (1953) & 74 Idaho 251 & $\begin{array}{l}\text { Sup. Ct., } \\
\text { Idaho }\end{array}$ \\
\hline 292 & $\begin{array}{l}\text { Choctaw; } \\
\text { Chickasaw }\end{array}$ & 22 June 1855 & 706 & 11 Stat. 611 & $\begin{array}{l}\text { Anthony v. Veatch } \\
(1950)\end{array}$ & 189 Or. 462 & $\begin{array}{l}\text { Sup. Ct., } \\
\text { Or. }\end{array}$ \\
\hline 292 & & 22 June 1855 & 706 & 11 Stat. 611 & $\begin{array}{l}\text { Wortham v. Walker } \\
\text { (1939) }\end{array}$ & 133 Tex. 255 & $\begin{array}{l}\text { Sup. Ct., } \\
\text { Tex. }\end{array}$ \\
\hline 293 & $\begin{array}{l}\text { Walla Walla; } \\
\text { Wasco }\end{array}$ & 25 June 1855 & 714 & 12 Stat. 963 & State v. Coffee (1976) & 97 Idaho 905 & $\begin{array}{l}\text { Sup. Ct., } \\
\text { Idaho }\end{array}$ \\
\hline 293 & & 25 June 1855 & 714 & 12 Stat. 963 & State v. Smith (1980) & $\begin{array}{l}1980 \text { Ore. App. } \\
\text { LEXIS } 4332\end{array}$ & $\begin{array}{l}\text { Ct. App., } \\
\text { Or. }\end{array}$ \\
\hline 293 & & 25 June 1855 & 714 & 12 Stat. 963 & State v. Smith (1981) & 51 Ore. App. 223 & $\begin{array}{l}\text { Ct. App., } \\
\text { Or. }\end{array}$ \\
\hline 293 & & 25 June 1855 & 714 & 12 Stat. 963 & State v. Jim (1986) & 81 Ore. App. 177 & $\begin{array}{l}\text { Ct. App., } \\
\text { Or. }\end{array}$ \\
\hline 293 & & 25 June 1855 & 714 & 12 Stat. 963 & State v. Jim (2002) & 178 Ore. App. 553 & $\begin{array}{l}\text { Ct. App., } \\
\text { Or. }\end{array}$ \\
\hline 293.1 & $\begin{array}{l}\text { Walla Walla; } \\
\text { Wasco }\end{array}$ & $\begin{array}{l}15 \text { November } \\
1865\end{array}$ & 908 & 14 Stat. 751 & Miles v. Veatch (1950) & 189 Ore. 506 & $\begin{array}{l}\text { Sup. Ct., } \\
\text { Or. }\end{array}$ \\
\hline 294 & $\begin{array}{l}\text { Quinault; } \\
\text { Quileute }\end{array}$ & $\begin{array}{l}1 \text { July } 1855, \\
\text { 25 January } 1856\end{array}$ & 719 & 12 Stat. 971 & $\begin{array}{l}\text { Pioneer Packing Co. v. } \\
\text { Winslow (1930) }\end{array}$ & 159 Wash. 655 & $\begin{array}{l}\text { Sup. Ct., } \\
\text { Wash. }\end{array}$ \\
\hline 294 & & $\begin{array}{l}1 \text { July } 1855 \text {, } \\
25 \text { January } 1856\end{array}$ & 719 & 12 Stat. 971 & $\begin{array}{l}\text { State v. Bertrand } \\
\text { (1963) }\end{array}$ & 61 Wash.2d 333 & $\begin{array}{l}\text { Sup. Ct., } \\
\text { Wash. }\end{array}$ \\
\hline 294 & & $\begin{array}{l}1 \text { July } 1855, \\
25 \text { January } 1856\end{array}$ & 719 & 12 Stat. 971 & $\begin{array}{l}\text { Department of Game v. } \\
\text { Puyallup Tribe, Inc. } \\
\text { (1972) }\end{array}$ & 80 Wash.2d 561 & $\begin{array}{l}\text { Sup. Ct., } \\
\text { Wash. }\end{array}$ \\
\hline 294 & & $\begin{array}{l}1 \text { July } 1855, \\
25 \text { January } 1856\end{array}$ & 719 & 12 Stat. 971 & State v. Coffee (1976) & 97 Idaho 905 & $\begin{array}{l}\text { Sup. Ct., } \\
\text { Idaho }\end{array}$ \\
\hline 294 & & $\begin{array}{l}1 \text { July } 1855, \\
25 \text { January } 1856\end{array}$ & 719 & 12 Stat. 971 & $\begin{array}{l}\text { Department of Game v. } \\
\text { Puyallup Tribe, Inc. } \\
\text { (1976) }\end{array}$ & 86 Wash.2d 664 & $\begin{array}{l}\text { Sup. Ct., } \\
\text { Wash. }\end{array}$ \\
\hline 294 & & $\begin{array}{l}1 \text { July } 1855, \\
25 \text { January } 1856\end{array}$ & 719 & 12 Stat. 971 & $\begin{array}{l}\text { Puget Sound } \\
\text { Gillnetters Assoc. v. } \\
\text { Moos (1979) }\end{array}$ & 92 Wash.2d 939 & $\begin{array}{l}\text { Sup. Ct., } \\
\text { Wash. }\end{array}$ \\
\hline
\end{tabular}


1 July 1855 ,
25 January 1856
1 July 1855 ,

1 July 1855 ,
25 January 1856

1 July 1855 ,

25 January 1856
1 July 1855

25 January 1856

Flathead;

Kutenai; Upper

Pend d'Oreille

16 July 1855

16 July 1855

722

16 July $1855 \quad 722$

16 July $1855 \quad 722$

16 July $1855 \quad 722$

16 July 1855

16 July $1855 \quad 722$

16 July $1855 \quad 722$

Ottawa;

Chippewa
31 July 1855

31 July $1855 \quad 725$

31 July $1855 \quad 725$
12 Stat. 97

12 Stat. 971

12 Stat. 971

12 Stat. 971

12 Stat. 975

State v. Goodell (1979)

State v. Cutler (1985)

Anderson and

Middleton Lumber Co.

v. Quinault Indian

Nation (1996)

State v. Buchanan

(1999)

State ex rel. Irvine v.

District Court (1951)

12 Stat. 975

12 Stat. 975

12 Stat. 975

12 Stat. 975

12 Stat. 975

12 Stat. 975

12 Stat. 975

12 Stat. 975

11 Stat. 621

11 Stat. 621

11 Stat. 621
State v. Pichette (1951)

State v. McClure

(1954)

In re Irvine (1962)

State v. Coffee (1976)

State v. Stasso (1977)

State v. Horseman

(1993)

State v. Buchanan

(1999)

State v. Shook (2002)

People v. Le Blanc

(1974)

People v. Le Blanc

(1976)

Attorney General v. Hermes (1983)
38 Ore. App. 511

109 Idaho 448

130 Wash.2d 862

20

138 Wash.2d 186

125 Mont. 398

125 Mont. 327

127 Mont. 534

140 Mont. 617

97 Idaho 905

172 Mont. 242

263 Mont. 87

138 Wash.2d 186

313 Mont. 347

55 Mich.

App. 684

399 Mich. 31

127 Mich.

App. 777
Ct. App.,

Or.

Sup. Ct.,

Idaho

Sup. Ct.,

Wash.

Sup. Ct.,

Wash.

Sup. Ct.,

Mont.

Sup. Ct.,

Mont.

Sup. Ct.,

Mont.

Sup. Ct.,

Mont.

Sup. Ct.,

Idaho

Sup. Ct.,

Mont.

Sup. Ct.,

Mont.

Sup. Ct.,

Wash.

Sup. Ct.

Mont.

Ct. App.,

Mich.

Sup. Ct.,

Mich.

Ct. App.,

Mich. 


Chippewa: Sault 2 August $1855 \quad 732$

Ste. Marie

299

\section{Blackfeet:}

17 October 1855736

Piegan and

Blood;

Gros Ventre;

Flathead; Upper

Pend d'Oreille;

Kutenai;

Nez Perce

Nez Perce

$\begin{array}{ll}17 \text { October } 1855 & 736 \\ 17 \text { October } 1855 & 736 \\ 5 \text { February } 1856 & 742 \\ & \\ 5 \text { February } 1856 & 742 \\ 11 \text { February } & 755 \\ 1856 & \\ 11 \text { February } & 755 \\ 1856 & \\ 11 \text { February } & 755 \\ 1856 & \\ 11 \text { February } & 755 \\ 1856 & \\ 11 \text { February } & 755 \\ 1856 & 767 \\ 5 \text { November } & 7857 \\ 19 \text { April } 1858 & 776 \\ 19 \text { April } 1858 & 776 \\ \text { 19 April } 1858 & 776\end{array}$

11 Stat. 631

People v. Le Blanc

\section{(1974)}

11 Stat. 657

Santa Rita Oil and Gas

Co. v. State Board of

Equalization (1936)

$\begin{array}{ll}\text { 55 Mich. } & \text { Ct. App., } \\ \text { App. } 684 & \text { Mich. } \\ \text { 101 Mont. } 268 & \text { Sup. Ct., } \\ & \text { Mont. }\end{array}$

\begin{tabular}{|c|c|c|c|}
\hline 11 Stat. 657 & $\begin{array}{l}\text { State v. Horseman } \\
\text { (1993) }\end{array}$ & 263 Mont. 87 & $\begin{array}{l}\text { Sup. Ct., } \\
\text { Mont. }\end{array}$ \\
\hline 11 Stat. 657 & $\begin{array}{l}\text { State ex rel. Martinez } \\
\text { v. Lewis (1993) }\end{array}$ & 116 N.M. 194 & $\begin{array}{l}\text { Ct. App., } \\
\text { N.M. }\end{array}$ \\
\hline 11 Stat. 663 & State v. Davids (1994) & 182 Wis.2d 186 & $\begin{array}{l}\text { Ct. App., } \\
\text { Wis. }\end{array}$ \\
\hline 11 Stat. 663 & State v. Davids (1995) & 194 Wis.2d 386 & $\begin{array}{l}\text { Sup. Ct., } \\
\text { Wis. }\end{array}$ \\
\hline 11 Stat. 679 & State v. Tucker (1941) & 237 Wis. 310 & $\begin{array}{l}\text { Sup. Ct., } \\
\text { Wis. }\end{array}$ \\
\hline 11 Stat. 679 & $\begin{array}{l}\text { Sturdevant v. State } \\
\text { (1977) }\end{array}$ & 76 Wis.2d 247 & $\begin{array}{l}\text { Sup. Ct., } \\
\text { Wis. }\end{array}$ \\
\hline 11 Stat. 679 & State v. Webster (1983) & 114 Wis.2d 418 & $\begin{array}{l}\text { Sup. Ct., } \\
\text { Wis. }\end{array}$ \\
\hline 11 Stat. 679 & State v. Davids (1994) & 182 Wis.2d 186 & $\begin{array}{l}\text { Ct. App., } \\
\text { Wis. }\end{array}$ \\
\hline 11 Stat. 679 & State v. Davids (1995) & 194 Wis.2d 386 & $\begin{array}{l}\text { Sup. Ct., } \\
\text { Wis. }\end{array}$ \\
\hline $\begin{array}{l}11 \text { Stat. } 735 \text {, } \\
12 \text { Stat. } 991\end{array}$ & $\begin{array}{l}\text { Hatch v. Luckman } \\
\text { (1909) }\end{array}$ & 155 A.D. 765 & $\begin{array}{l}\text { Sup. Ct., } \\
\text { N.Y. }\end{array}$ \\
\hline 11 Stat. 743 & $\begin{array}{l}\text { Wood v. Jameson } \\
\text { (1964) }\end{array}$ & 81 S.D. 12 & $\begin{array}{l}\text { Sup. Ct., } \\
\text { S.D. }\end{array}$ \\
\hline 11 Stat. 743 & $\begin{array}{l}\text { State v. Williamson } \\
\text { (1973) }\end{array}$ & 87 S.D. 512 & $\begin{array}{l}\text { Sup. Ct., } \\
\text { S.D. }\end{array}$ \\
\hline 11 Stat. 743 & $\begin{array}{l}\text { State v. Thompson } \\
\text { (1984) }\end{array}$ & 355 N.W.2d 349 & $\begin{array}{l}\text { Sup. Ct., } \\
\text { S.D. }\end{array}$ \\
\hline
\end{tabular}

State v. 


\begin{tabular}{|c|c|c|c|c|c|c|c|}
\hline 307 & & 19 April 1858 & 776 & 11 Stat. 743 & State v. Greger (1997) & 559 N.W.2d 854 & $\begin{array}{l}\text { Sup. Ct., } \\
\text { S.D. }\end{array}$ \\
\hline 312 & Sac and Fox & 1 October 1859 & 796 & 15 Stat. 467 & $\begin{array}{l}\text { Pennock v. Monroe } \\
(1870)\end{array}$ & 5 Kan. 578 & $\begin{array}{l}\text { Sup. Ct., } \\
\text { Kan. }\end{array}$ \\
\hline 313 & Kansa & 5 October 1859 & 800 & 12 Stat. 1111 & $\begin{array}{l}\text { Grinter v. Kansas } \\
\text { Pacific Railway Co. } \\
\text { (1880) }\end{array}$ & 23 Kan. 642 & $\begin{array}{l}\text { Sup. Ct., } \\
\text { Kan. }\end{array}$ \\
\hline 313 & & 5 October 1859 & 800 & 12 Stat. 1111 & $\begin{array}{l}\text { Webster v. Cooke } \\
(1880)\end{array}$ & 23 Kan. 637 & $\begin{array}{l}\text { Sup. Ct., } \\
\text { Kan. }\end{array}$ \\
\hline 314 & Delaware & 30 May 1860 & 803 & 12 Stat. 1129 & $\begin{array}{l}\text { Grinter v. Kansas } \\
\text { Pacific Railway Co. } \\
\text { (1880) }\end{array}$ & 24 Kan. 642 & $\begin{array}{l}\text { Sup. Ct., } \\
\text { Kan. }\end{array}$ \\
\hline 318 & Potawatomi & $\begin{array}{l}15 \text { November } \\
1861\end{array}$ & 824 & 12 Stat. 1191 & $\begin{array}{l}\text { Maynes v. Veale } \\
(1878)\end{array}$ & 20 Kan. 374 & $\begin{array}{l}\text { Sup. Ct., } \\
\text { Kan. }\end{array}$ \\
\hline 318 & & $\begin{array}{l}15 \text { November } \\
1861\end{array}$ & 824 & 12 Stat. 1191 & $\begin{array}{l}\text { Veale v. Maynes } \\
\text { (1879) }\end{array}$ & 23 Kan. 1 & $\begin{array}{l}\text { Sup. Ct., } \\
\text { Kan. }\end{array}$ \\
\hline 318 & & $\begin{array}{l}15 \text { November } \\
1861\end{array}$ & 824 & 12 Stat. 1191 & In re Kaul (1997) & 261 Kan. 755 & $\begin{array}{l}\text { Sup. Ct., } \\
\text { Kan. }\end{array}$ \\
\hline 318 & & $\begin{array}{l}15 \text { November } \\
1861\end{array}$ & 824 & 12 Stat. 1191 & In re Kaul (2000) & 269 Kan. 181 & $\begin{array}{l}\text { Sup. Ct., } \\
\text { Kan. }\end{array}$ \\
\hline 320 & $\begin{array}{l}\text { Ottawa: } \\
\text { Blanchard's } \\
\text { Fork; Ottawa: } \\
\text { Roche de Boeuf }\end{array}$ & 24 June 1862 & 830 & 12 Stat. 1237 & $\begin{array}{l}\text { McCullagh v. Allen } \\
\text { (1872) }\end{array}$ & 10 Kan. 150 & $\begin{array}{l}\text { Sup. Ct., } \\
\text { Kan. }\end{array}$ \\
\hline 320 & & 24 June 1862 & 830 & 12 Stat. 1237 & $\begin{array}{l}\text { Campbell v. Paramore } \\
\text { (1877) }\end{array}$ & 17 Kan. 639 & $\begin{array}{l}\text { Sup. Ct., } \\
\text { Kan. }\end{array}$ \\
\hline 320 & & 24 June 1862 & 830 & 12 Stat. 1237 & Wiggin v. King (1886) & 35 Kan. 410 & $\begin{array}{l}\text { Sup. Ct., } \\
\text { Kan. }\end{array}$ \\
\hline 320 & & 24 June 1862 & 830 & 12 Stat. 1237 & $\begin{array}{l}\text { Board of Commis- } \\
\text { sioners of Miami } \\
\text { County v. Godfroy } \\
(1901)\end{array}$ & 27 Ind. App. 610 & $\begin{array}{l}\text { Ct. App., } \\
\text { Ind. }\end{array}$ \\
\hline 320 & & 24 June 1862 & 830 & 12 Stat. 1237 & $\begin{array}{l}\text { Stevens v. Elliott } \\
\text { (1911) }\end{array}$ & 30 Okla. 41 & $\begin{array}{l}\text { Sup. Ct., } \\
\text { Okla. }\end{array}$ \\
\hline
\end{tabular}




\begin{tabular}{|c|c|c|c|c|c|c|c|}
\hline 321 & Kickapoo & 28 June 1862 & 835 & 13 Stat. 623 & $\begin{array}{l}\text { Parker v. Winsor } \\
(1870)\end{array}$ & 5 Kan. 362 & $\begin{array}{l}\text { Sup. Ct., } \\
\text { Kan. }\end{array}$ \\
\hline 321 & & 28 June 1862 & 835 & 13 Stat. 623 & $\begin{array}{l}\text { Central Branch Union } \\
\text { Pacific Railroad Co. v. } \\
\text { Wilcox (1875) }\end{array}$ & 14 Kan. 259 & $\begin{array}{l}\text { Sup. Ct., } \\
\text { Kan. }\end{array}$ \\
\hline 321 & & 28 June 1862 & 835 & 13 Stat. 623 & $\begin{array}{l}\text { Briggs v. McClain } \\
(1890)\end{array}$ & 43 Kan. 653 & $\begin{array}{l}\text { Sup. Ct., } \\
\text { Kan. }\end{array}$ \\
\hline 321 & & 28 June 1862 & 835 & 13 Stat. 623 & $\begin{array}{l}\text { Stevens v. Elliott } \\
\text { (1911) }\end{array}$ & 30 Okla. 41 & $\begin{array}{l}\text { Sup. Ct., } \\
\text { Okla. }\end{array}$ \\
\hline 321 & & 28 June 1862 & 835 & 13 Stat. 623 & $\begin{array}{l}\text { State v. Big Sheep } \\
\text { (1926) }\end{array}$ & 75 Mont. 219 & $\begin{array}{l}\text { Sup. Ct., } \\
\text { Mont. }\end{array}$ \\
\hline 322 & $\begin{array}{l}\text { Chippewa: } \\
\text { Mississippi, } \\
\text { Pillager and } \\
\text { Lake } \\
\text { Winnibigoshish }\end{array}$ & 11 March 1863 & 839 & 12 Stat. 1249 & White v. Wright (1901) & 83 Minn. 222 & $\begin{array}{l}\text { Sup. Ct., } \\
\text { Minn. }\end{array}$ \\
\hline 322 & & 11 March 1863 & 839 & 12 Stat. 1249 & State v. Forge (1977) & 262 N.W.2d 341 & $\begin{array}{l}\text { Sup. Ct., } \\
\text { Minn. }\end{array}$ \\
\hline 323 & Nez Perce & 9 June 1863 & 843 & 14 Stat. 647 & $\begin{array}{l}\text { State v. McConville } \\
\text { (1943) }\end{array}$ & 65 Idaho 46 & $\begin{array}{l}\text { Sup. Ct., } \\
\text { Idaho }\end{array}$ \\
\hline 323 & & 9 June 1863 & 843 & 14 Stat. 647 & State v. Arthur (1953) & 74 Idaho 251 & $\begin{array}{l}\text { Sup. Ct., } \\
\text { Idaho }\end{array}$ \\
\hline 327 & $\begin{array}{l}\text { Chippewa: } \\
\text { Red Lake and } \\
\text { Pembina }\end{array}$ & 2 October 1863 & 853 & 13 Stat. 667 & $\begin{array}{l}\text { State v. Holthusen } \\
\text { (1962) }\end{array}$ & 261 Minn. 536 & $\begin{array}{l}\text { Sup. Ct., } \\
\text { Minn. }\end{array}$ \\
\hline 327 & & 2 October 1863 & 853 & 13 Stat. 667 & $\begin{array}{l}\text { Topash v. } \\
\text { Commissioner of } \\
\text { Revenue (1980) }\end{array}$ & 291 N.W.2d 679 & $\begin{array}{l}\text { Sup. Ct., } \\
\text { Minn. }\end{array}$ \\
\hline 327.1 & $\begin{array}{l}\text { Chippewa: } \\
\text { Red Lake and } \\
\text { Pembina }\end{array}$ & 12 April 1864 & 861 & 13 Stat. 689 & $\begin{array}{l}\text { Topash v. } \\
\text { Commissioner of } \\
\text { Revenue (1980) }\end{array}$ & 291 N.W.2d 679 & $\begin{array}{l}\text { Sup. Ct., } \\
\text { Minn. }\end{array}$ \\
\hline 330 & $\begin{array}{l}\text { Chippewa: } \\
\text { Red Lake and } \\
\text { Pembina }\end{array}$ & 12 April 1864 & 861 & 13 Stat. 689 & $\begin{array}{l}\text { Topash v. Commis- } \\
\text { sioner of Revenue } \\
\text { (1980) }\end{array}$ & 291 N.W.2d 679 & $\begin{array}{l}\text { Sup. Ct., } \\
\text { Minn. }\end{array}$ \\
\hline
\end{tabular}




\begin{tabular}{|c|c|c|c|c|c|c|c|}
\hline 331 & $\begin{array}{l}\text { Chippewa: } \\
\text { Mississippi, } \\
\text { Pillager and } \\
\text { Lake } \\
\text { Winnibigoshish }\end{array}$ & 7 May 1864 & 862 & 13 Stat. 693 & $\begin{array}{l}\text { Vachon v. } \\
\text { Nichols-Chisholm } \\
\text { Lumber Co. (1914) }\end{array}$ & 126 Minn. 303 & $\begin{array}{l}\text { Sup. Ct., } \\
\text { Minn. }\end{array}$ \\
\hline 331 & & 7 May 1864 & 862 & 13 Stat. 693 & State v. Forge (1977) & 262 N.W.2d 341 & $\begin{array}{l}\text { Sup. Ct., } \\
\text { Minn. }\end{array}$ \\
\hline 331 & & 7 May 1864 & 862 & 13 Stat. 693 & State v. Clark (1979) & 282 N.W.2d 902 & $\begin{array}{l}\text { Sup. Ct., } \\
\text { Minn. }\end{array}$ \\
\hline 332 & $\begin{array}{l}\text { Klamath; } \\
\text { Modoc; Paiute: } \\
\text { Yahooskin }\end{array}$ & 14 October 1864 & 865 & 16 Stat. 707 & $\begin{array}{l}\text { Anderson v. Britton } \\
\text { (1957) }\end{array}$ & 212 Ore. 1 & $\begin{array}{l}\text { Sup. Ct., } \\
\text { Or. }\end{array}$ \\
\hline 332 & & 14 October 1864 & 865 & 16 Stat. 707 & $\begin{array}{l}\text { State v. Bojorcas } \\
\text { (1973) }\end{array}$ & $\begin{array}{l}14 \text { Ore. } \\
\text { App. } 538\end{array}$ & $\begin{array}{l}\text { Ct. App., } \\
\text { Or. }\end{array}$ \\
\hline 332 & & 14 October 1864 & 865 & 16 Stat. 707 & $\begin{array}{l}\text { Markley v. Department } \\
\text { of Revenue (2002) }\end{array}$ & $\begin{array}{l}2002 \text { Ore. Tax } \\
\text { LEXIS } 32\end{array}$ & $\begin{array}{l}\text { Tax Ct., } \\
\text { Or. }\end{array}$ \\
\hline 334 & Omaha & 6 March 1865 & 872 & 14 Stat. 667 & Brader v. James (1916) & 49 Okla. 734 & $\begin{array}{l}\text { Sup. Ct., } \\
\text { Okla. }\end{array}$ \\
\hline 334 & & 6 March 1865 & 872 & 14 Stat. 667 & $\begin{array}{l}\text { Highrock v. Gavin } \\
(1920)\end{array}$ & 43 S.D. 315 & $\begin{array}{l}\text { Sup. Ct., } \\
\text { S.D. }\end{array}$ \\
\hline 338 & $\begin{array}{l}\text { Osage: Grand } \\
\text { and Little }\end{array}$ & $\begin{array}{l}29 \text { September } \\
1865\end{array}$ & 878 & 14 Stat. 687 & $\begin{array}{l}\text { Lownsberry v. } \\
\text { Rakestraw (1875) }\end{array}$ & 14 Kan. 151 & $\begin{array}{l}\text { Sup. Ct., } \\
\text { Kan. }\end{array}$ \\
\hline 338 & & $\begin{array}{l}29 \text { September } \\
1865\end{array}$ & 878 & 14 Stat. 687 & $\begin{array}{l}\text { Jarvis v. Campbell } \\
\text { (1880) }\end{array}$ & 23 Kan. 370 & $\begin{array}{l}\text { Sup. Ct., } \\
\text { Kan. }\end{array}$ \\
\hline 338 & & $\begin{array}{l}29 \text { September } \\
1865\end{array}$ & 878 & 14 Stat. 687 & $\begin{array}{l}\text { Baker v. Newland } \\
\text { (1881) }\end{array}$ & 25 Kan. 25 & $\begin{array}{l}\text { Sup. Ct., } \\
\text { Kan. }\end{array}$ \\
\hline 338 & & $\begin{array}{l}29 \text { September } \\
1865\end{array}$ & 878 & 14 Stat. 687 & $\begin{array}{l}\text { Missouri, Kansas and } \\
\text { Texas Railway Co. v. } \\
\text { Watson (1906) }\end{array}$ & 74 Kan. 494 & $\begin{array}{l}\text { Sup. Ct., } \\
\text { Kan. }\end{array}$ \\
\hline 351 & $\begin{array}{l}\text { Walla Walla; } \\
\text { Wasco }\end{array}$ & $\begin{array}{l}15 \text { November } \\
1865\end{array}$ & 908 & 14 Stat 751 & Miles v. Veatch (1950) & 189 Ore. 506 & $\begin{array}{l}\text { Sup. Ct., } \\
\text { Or. }\end{array}$ \\
\hline 353 & Potawatomi & 29 March 1866 & 916 & 14 Stat. 763 & $\begin{array}{l}\text { Board of } \\
\text { Commissioners of } \\
\text { Miami County v. } \\
\text { Godfroy (1901) }\end{array}$ & $\begin{array}{l}27 \text { Ind. } \\
\text { App. } 610\end{array}$ & $\begin{array}{l}\text { Ct. App., } \\
\text { Ind. }\end{array}$ \\
\hline
\end{tabular}




\begin{tabular}{|c|c|c|c|c|c|c|c|}
\hline 355 & $\begin{array}{l}\text { Choctaw; } \\
\text { Chickasaw }\end{array}$ & 28 April 1866 & 918 & 14 Stat. 769 & $\begin{array}{l}\text { Allen v. Trimmer } \\
\text { (1914) }\end{array}$ & 45 Okla. 83 & $\begin{array}{l}\text { Sup. Ct., } \\
\text { Okla. }\end{array}$ \\
\hline 356 & Creek & 14 June 1866 & 931 & 14 Stat. 785 & $\begin{array}{l}\text { Bruner v. Oswald } \\
\text { (1919) }\end{array}$ & 72 Okla. 42 & $\begin{array}{l}\text { Sup. Ct., } \\
\text { Okla. }\end{array}$ \\
\hline 356 & & 14 June 1866 & 931 & 14 Stat. 785 & $\begin{array}{l}\text { Board of Com'rs of } \\
\text { Okfuskee County v. } \\
\text { Hutton (1919) }\end{array}$ & 72 Okla. 223 & $\begin{array}{l}\text { Sup. Ct., } \\
\text { Okla. }\end{array}$ \\
\hline 356 & & 14 June 1866 & 931 & 14 Stat. 785 & $\begin{array}{l}\text { Noble v. Oklahoma } \\
\text { City (1935) }\end{array}$ & 172 Okla. 182 & $\begin{array}{l}\text { Sup. Ct., } \\
\text { Okla. }\end{array}$ \\
\hline 357 & Delaware & 4 July 1866 & 937 & 14 Stat. 793 & $\begin{array}{l}\text { White v. Starbuck } \\
\text { (1913) }\end{array}$ & 41 Okla. 50 & $\begin{array}{l}\text { Sup. Ct., } \\
\text { Okla. }\end{array}$ \\
\hline 358 & Cherokee & 19 July 1866 & 942 & 14 Stat. 799 & $\begin{array}{l}\text { Robinson v. Owen } \\
\text { (1911) }\end{array}$ & 30 Okla. 484 & $\begin{array}{l}\text { Sup. Ct., } \\
\text { Okla. }\end{array}$ \\
\hline 358 & & 19 July 1866 & 942 & 14 Stat. 799 & $\begin{array}{l}\text { In re McDade's Estate } \\
\text { (1923) }\end{array}$ & 95 Okla. 120 & $\begin{array}{l}\text { Sup. Ct., } \\
\text { Okla. }\end{array}$ \\
\hline 358 & & & & & $\begin{array}{l}\text { Aladdin Petroleum } \\
\text { Corp. v. State ex rel. } \\
\text { Commissioners of } \\
\text { Land Office (1948) }\end{array}$ & 200 Okla. 134 & $\begin{array}{l}\text { Sup. Ct., } \\
\text { Okla. }\end{array}$ \\
\hline 358 & & 19 July 1866 & 942 & 14 Stat. 799 & C.M.G. v. State (1979) & 594 P.2d 798 & $\begin{array}{l}\text { Ct. Crim. } \\
\text { App., Okla. }\end{array}$ \\
\hline 360 & $\begin{array}{l}\text { Sioux: Sisseton } \\
\text { and Wahpeton }\end{array}$ & $\begin{array}{l}19 \text { February } \\
1867\end{array}$ & 956 & 15 Stat. 505 & State v. Lohnes (1955) & 69 N.W.2d 508 & $\begin{array}{l}\text { Sup. Ct., } \\
\text { N.D. }\end{array}$ \\
\hline 360 & & $\begin{array}{l}19 \text { February } \\
1867\end{array}$ & 956 & 15 Stat. 505 & $\begin{array}{l}\text { In re De Marrias } \\
(1958)\end{array}$ & 77 S.D. 294 & $\begin{array}{l}\text { Sup. Ct., } \\
\text { S.D. }\end{array}$ \\
\hline 360 & & $\begin{array}{l}19 \text { February } \\
1867\end{array}$ & 956 & 15 Stat. 505 & $\begin{array}{l}\text { De Coteau v. District } \\
\text { County Court (1973) }\end{array}$ & 87 S.D. 555 & $\begin{array}{l}\text { Sup. Ct., } \\
\text { S.D. }\end{array}$ \\
\hline 360 & & $\begin{array}{l}19 \text { February } \\
1867\end{array}$ & 956 & 15 Stat. 505 & $\begin{array}{l}\text { In re Application of } \\
\text { Otter Tail Power Co. } \\
\text { (1990) }\end{array}$ & 451 N.W.2d 95 & $\begin{array}{l}\text { Sup. Ct., } \\
\text { N.D. }\end{array}$ \\
\hline
\end{tabular}


Shawnee;

Quapaw; Peoria;

Kaskaskia; Wea;

Piankashaw;

Miami; Ottawa:

Blanchard's

Fork; Ottawa:

Roche de Boeuf;

Wyandot

\section{Chippewa:}

Mississippi

$\begin{array}{ll}23 \text { February } & 960 \\ 1867 & \\ 23 \text { February } & 960 \\ 1867 & \\ 23 \text { February } & 960 \\ 1867 & \\ 27 \text { February } & 970 \\ 1867 & \\ \begin{array}{l}27 \text { February } \\ 1867\end{array} & 970 \\ 19 \text { March } 1867 & 974 \\ & \\ 19 \text { March } 1867 & 974 \\ 19 \text { March } 1867 & 974 \\ 19 \text { March } 1867 & 974 \\ \text { 19 March } 1867 & 974 \\ \text { 19 March } 1867 & 974\end{array}$

15 Stat. 513

15 Stat. 513

15 Stat. 513

15 Stat. 531

15 Stat. 531

16 Stat. 719

16 Stat. 719

16 Stat. 719

16 Stat. 719

16 Stat. 719

16 Stat. 719
Kan.

Sup. Ct.

Kan

Sup. Ct.,

Okla.

Ct. Crim.

App., Okla.

Sup. Ct.,

Kan.

Sup. Ct.,

Kan.

Sup. Ct., Minn.
Sup. Ct.,

Minn.

Sup. Ct.,

Minn.

Sup. Ct.,

Minn.

Sup. Ct.,

Minn.

Sup. Ct.,

Minn.

711 P.2d 77 (1985)

Hanes v. State (1998) 973 P.2d 330

Maynes v. Veale

20 Kan. 374

Nichols-Chisholm

Lumber Co. (1914)

Sanders v. Morrison (1923)

State v. Cloud (1930) 179 Minn. 180

State v. Bush (1935)

195 Minn. 413

State v. Forge (1977)

262 N.W.2d 341

282 N.W.2d 902 


\begin{tabular}{|c|c|c|c|c|c|c|c|}
\hline 363 & & 19 March 1867 & 974 & 16 Stat. 719 & State v. St. Clair (1997) & 560 N.W.2d 732 & $\begin{array}{l}\text { Ct. App., } \\
\text { Minn }\end{array}$ \\
\hline 364 & $\begin{array}{l}\text { Kiowa; } \\
\text { Comanche }\end{array}$ & 21 October 1867 & 977 & 15 Stat. 581 & $\begin{array}{l}\text { Hoover v. Kiowa Tribe } \\
\text { (1998) }\end{array}$ & 957 P.2d 81 & $\begin{array}{l}\text { Sup. Ct., } \\
\text { Okla. }\end{array}$ \\
\hline 366 & $\begin{array}{l}\text { Cheyenne; } \\
\text { Arapaho }\end{array}$ & 28 October 1867 & 984 & 15 Stat. 593 & $\begin{array}{l}\text { Aladdin Petroleum } \\
\text { Corp. v. State ex rel. } \\
\text { Commissioners of } \\
\text { Land Office (1948) }\end{array}$ & 200 Okla. 134 & $\begin{array}{l}\text { Sup. Ct., } \\
\text { Okla. }\end{array}$ \\
\hline 367 & $\begin{array}{l}\text { Ute: } \\
\text { Tabeguache, } \\
\text { Muache, } \\
\text { Capote, } \\
\text { Wiminuche, } \\
\text { Yampa, } \\
\text { Grand River and } \\
\text { Uintah }\end{array}$ & 2 March 1868 & 990 & 15 Stat. 619 & $\begin{array}{l}\text { In re General } \\
\text { Adjudication of All } \\
\text { Rights to Use Water in } \\
\text { Big Horn River System } \\
\text { (1988) }\end{array}$ & 753 P.2d 76 & $\begin{array}{l}\text { Sup. Ct., } \\
\text { Wyo. }\end{array}$ \\
\hline 369 & $\begin{array}{l}\text { Sioux: } \\
\text { Brule, Oglala, } \\
\text { Miniconjou, } \\
\text { Yanktonai, } \\
\text { Hunkpapa, } \\
\text { Blackfeet, } \\
\text { Cuthead, } \\
\text { Two Kettle, } \\
\text { Sans Arcs and } \\
\text { Santee; Arapaho }\end{array}$ & 29 April 1868 & 998 & 15 Stat. 635 & $\begin{array}{l}\text { Anderson v. Brule } \\
\text { County (1940) }\end{array}$ & 67 S.D. 308 & $\begin{array}{l}\text { Sup. Ct., } \\
\text { S.D. }\end{array}$ \\
\hline 369 & & 29 April 1868 & 998 & 15 Stat. 635 & State v. Molash (1972) & 86 S.D. 558 & $\begin{array}{l}\text { Sup. Ct., } \\
\text { S.D. }\end{array}$ \\
\hline 369 & & 29 April 1868 & 998 & 15 Stat. 635 & State v. Powless (1978) & 265 N.W.2d 143 & $\begin{array}{l}\text { Sup. Ct., } \\
\text { S.D. }\end{array}$ \\
\hline 369 & & 29 April 1868 & 998 & 15 Stat. 635 & $\begin{array}{l}\text { State v. Brave Heart } \\
\text { (1982) }\end{array}$ & 326 N.W.2d 220 & $\begin{array}{l}\text { Sup. Ct., } \\
\text { S.D. }\end{array}$ \\
\hline 370 & Crow & 7 May 1868 & 1008 & 15 Stat. 649 & $\begin{array}{l}\text { Higgins v. Brown } \\
\text { (1908) }\end{array}$ & 20 Okla. 355 & $\begin{array}{l}\text { Sup. Ct., } \\
\text { Okla. }\end{array}$ \\
\hline
\end{tabular}




$$
1008
$$

10 May 1868

1012

1015
15 Stat. 649

15 Stat. 649

15 Stat. 649

15 Stat. 649

15 Stat. 649

15 Stat. 649

15 Stat. 649

15 Stat. 649

15 Stat. 649

15 Stat. 649

15 Stat. 649

State v. Big Sheep

(1926)

Anderson v. Spear-

Morgan Livestock Co.

(1938)

Neah Bay Fish Co. v. 3 Wash.2d 570

Krummel (1940)

Cook v. Hudson (1940) 110 Mont. 263

Bennett v. Seattle

(1945)

Merrill v. Bishop

(1951)

Lewis v. Hanson

(1951)

Wakefield v. Little

Light (1975)

In re Little Light

(1979)

State v. Cutler (1985)

In re General

Adjudication of All

Rights to Use Water in

Big Horn River System (1988)

15 Stat. 655

In re General

Adjudication of All

Rights to Use Water in

Big Horn River System

(1988)

15 Stat. 667

Harriso

(1948)

15 Stat. 667

Begay v. Miller (1950)
75 Mont. 219

107 Mont. 18

22 Wash.2d 455

69 Wyo. 45

124 Mont. 492

276 Md. 333

183 Mont. 52

109 Idaho 448

753 P.2d 76

Sup. Ct.,

Mont.

Sup. Ct., Mont.

Sup. Ct., Wash.

Sup. Ct.,

Mont.

Sup. Ct.,

Wash.

Sup. Ct.,

Wyo.

Sup. Ct.,

Mont.

Ct. App.,

Md.

Sup. Ct.,

Mont.

Sup. Ct.,

Idaho

Sup. Ct.,

Wyo.

753 P.2d 76

Sup. Ct., Wyo.

Sup. Ct.,

Ariz.

Sup. Ct.,

Ariz. 


\begin{tabular}{|c|c|c|c|c|c|c|}
\hline 372 & 1 June 1868 & 1015 & 15 Stat. 667 & $\begin{array}{l}\text { Young v. Felornia } \\
(1952)\end{array}$ & 121 Utah 646 & $\begin{array}{l}\text { Sup. Ct., } \\
\text { Utah }\end{array}$ \\
\hline 372 & 1 June 1868 & 1015 & 15 Stat. 667 & Williams v. Lee (1958) & 83 Ariz. 241 & $\begin{array}{l}\text { Sup. Ct., } \\
\text { Ariz. }\end{array}$ \\
\hline 372 & 1 June 1868 & 1015 & 15 Stat. 667 & $\begin{array}{l}\text { Montoya v. Bolack } \\
\text { (1962) }\end{array}$ & 70 N.M. 196 & $\begin{array}{l}\text { Sup. Ct., } \\
\text { N.M. }\end{array}$ \\
\hline 372 & 1 June 1868 & 1015 & 15 Stat. 667 & $\begin{array}{l}\text { Jim v. CIT Financial } \\
\text { Services Corp. (1974) }\end{array}$ & 86 N.M. 784 & $\begin{array}{l}\text { Ct. App., } \\
\text { N.M. }\end{array}$ \\
\hline 372 & 1 June 1868 & 1015 & 15 Stat. 667 & $\begin{array}{l}\text { Fox v. Bureau of } \\
\text { Revenue (1975) }\end{array}$ & 87 N.M. 261 & $\begin{array}{l}\text { Ct. App., } \\
\text { N.M. }\end{array}$ \\
\hline 372 & 1 June 1868 & 1015 & 15 Stat. 667 & $\begin{array}{l}\text { Brown v. Babbitt Ford } \\
\text { (1977) }\end{array}$ & 117 Ariz. 192 & $\begin{array}{l}\text { Ct. App., } \\
\text { Ariz. }\end{array}$ \\
\hline 372 & 1 June 1868 & 1015 & 15 Stat. 667 & $\begin{array}{l}\text { State ex rel. Peterson v. } \\
\text { District Court (1980) }\end{array}$ & 617 P.2d 1056 & $\begin{array}{l}\text { Sup. Ct., } \\
\text { Wyo. }\end{array}$ \\
\hline 372 & 1 June 1868 & 1015 & 15 Stat. 667 & $\begin{array}{l}\text { Johnson v. } \\
\text { Kerr-McGee Oil } \\
\text { Industries (1981) }\end{array}$ & 129 Ariz. 393 & $\begin{array}{l}\text { Ct. App., } \\
\text { Ariz. }\end{array}$ \\
\hline 372 & 1 June 1868 & 1015 & 15 Stat. 667 & $\begin{array}{l}\text { Blatchford v. Gonzales } \\
\text { (1983) }\end{array}$ & 100 N.M. 333 & $\begin{array}{l}\text { Sup. Ct., } \\
\text { N.M. }\end{array}$ \\
\hline 372 & 1 June 1868 & 1015 & 15 Stat. 667 & State v. Flint (1988) & 157 Ariz. 227 & $\begin{array}{l}\text { Ct. App., } \\
\text { Ariz. }\end{array}$ \\
\hline 372 & 1 June 1868 & 1015 & 15 Stat. 667 & $\begin{array}{l}\text { In re General } \\
\text { Adjudication of All } \\
\text { Rights to Use Water in } \\
\text { Big Horn River System } \\
\text { (1988) }\end{array}$ & 753 P.2d 76 & $\begin{array}{l}\text { Sup. Ct., } \\
\text { Wyo. }\end{array}$ \\
\hline 372 & 1 June 1868 & 1015 & 15 Stat. 667 & $\begin{array}{l}\text { Texaco, Inc. v. San } \\
\text { Juan County (1994) }\end{array}$ & 869 P.2d 942 & $\begin{array}{l}\text { Sup. Ct., } \\
\text { Utah }\end{array}$ \\
\hline 372 & 1 June 1868 & 1015 & 15 Stat. 667 & $\begin{array}{l}\text { Begay v. Superior } \\
\text { Court (1994) }\end{array}$ & $\begin{array}{l}1994 \text { Ariz. App. } \\
\text { LEXIS } 179\end{array}$ & $\begin{array}{l}\text { Ct. App., } \\
\text { Ariz. }\end{array}$ \\
\hline 372 & 1 June 1868 & 1015 & 15 Stat. 667 & $\begin{array}{l}\text { Maryboy v. Utah State } \\
\text { Tax Commission } \\
\text { (1995) }\end{array}$ & 904 P.2d 662 & $\begin{array}{l}\text { Sup. Ct., } \\
\text { Utah }\end{array}$ \\
\hline 372 & 1 June 1868 & 1015 & 15 Stat. 667 & State v. Zaman (1996) & 187 Ariz. 81 & $\begin{array}{l}\text { Ct. App., } \\
\text { Ariz. }\end{array}$ \\
\hline
\end{tabular}


Commissioners of

Fremont County

3 July 1868

1020

3 July 1868

1020

3 July 1868

1020

3 July 1868

1020

3 July 1868

1020

3 July 1868

1020

3 July 1868

1020

3 July 1868

1020

3 July 1868

1020

3 July 1868

1020

3 July 1868

1020
15 Stat. 673

15 Stat. 673

15 Stat. 673

15 Stat. 673

15 Stat. 673

15 Stat. 673

15 Stat. 673

15 Stat. 673

15 Stat. 673

15 Stat. 673
(1935)

State v. Tulee (1941) 7 Wash.2d 124

Merrill v. Bishop

(1951)

State v. Arthur (1953) 74 Idaho 251

Merrill v. Bishop

(1955)

Metlakatla Indian

Community v. Egan

(1961)

State v. Moss (1970) 471 P.2d 333

State v. Tinno (1972) 94 Idaho 759

State ex rel. Peterson v. 617 P.2d 1056

District Court (1980)

State v. Cutler (1985)

In re General

Adjudication

of All Rights to Use

Water in Big

Horn River System

(1988)

15 Stat. $673 \quad$ In re General

Adjudication

of All Rights to Use

Water in Big Horn

River System (1992)
109 Idaho 448

Wyo.

Sup. Ct.

Wash.

Sup. Ct.,

Wyo.

Sup. Ct.,

Idaho

Sup. Ct.,

Wyo.

Sup. Ct.,

Alaska

Sup. Ct., Wyo.

Sup. Ct., Idaho

Sup. Ct., Wyo.

Sup. Ct., Idaho

Sup. Ct.,

Wyo.

753 P. 2 d 76

835 P.2d 273

Sup. Ct., Wyo. 
Table 1 (continued)

\begin{tabular}{|c|c|c|c|c|c|c|c|}
\hline 373 & & 3 July 1868 & 1020 & 15 Stat. 673 & $\begin{array}{l}\text { Riverton Valley } \\
\text { Irrigation District } \\
\text { v. Big Horn Canal } \\
\text { Association } \\
\text { (In re General } \\
\text { Adjudication } \\
\text { of All Rights to Use } \\
\text { Water in the Big Horn } \\
\text { River System) (1995) }\end{array}$ & 899 P.2d 848 & $\begin{array}{l}\text { Sup. Ct., } \\
\text { Wyo. }\end{array}$ \\
\hline 374 & Nez Perce & 13 August 1868 & 1024 & 15 Stat. 693 & $\begin{array}{l}\text { State v. McConville } \\
\text { (1943) }\end{array}$ & 65 Idaho 46 & $\begin{array}{l}\text { Sup. Ct., } \\
\text { Idaho }\end{array}$ \\
\hline 374 & & 13 August 1868 & 1024 & 15 Stat. 693 & State v. Arthur (1953) & 74 Idaho 251 & $\begin{array}{l}\text { Sup. Ct., } \\
\text { Idaho }\end{array}$ \\
\hline 999 & $\begin{array}{l}\text { Sioux; } \\
\text { Cheyenne; } \\
\text { Arapaho; } \\
\text { Crow; } \\
\text { Assiniboin; } \\
\text { Gros } \\
\text { Ventres; } \\
\text { Mandan; } \\
\text { Arikara }\end{array}$ & $\begin{array}{l}17 \text { September } \\
1851\end{array}$ & 594 & 11 Stat. 749 & $\begin{array}{l}\text { State v. Horseman } \\
\text { (1993) }\end{array}$ & 263 Mont. 87 & $\begin{array}{l}\text { Sup. Ct., } \\
\text { Mont. }\end{array}$ \\
\hline
\end{tabular}


In State v. McConville, ${ }^{29}$ a Nez Perce man was arrested for fishing without a State fish and game license in a stream that ran originally within the Nez Perce reservation. The defense centered on Article 3 of the Treaty with the Nez Perces, 1855, ${ }^{30}$ that assured the "right of taking fish at all usual and accustomed places in common with citizens of the Territory," and on two subsequent treaties ${ }^{31}$ that reconfirmed these rights. In citing the United States Supreme Court case Tulee v. Washington, ${ }^{32}$ and the similarity between the 1855 Nez Perce treaty and the one under consideration in Tulee, ${ }^{33}$ the Supreme Court of Idaho concluded that "the Tulee case is a comprehensive and complete vindication of the right of the Indian to fish without a license by reason of the rights reserved to him, not granted, in the original treaty and by successive treaties reaffirmed, or, at least, not abrogated."34

A decade later, in State v. Arthur, ${ }^{35}$ a Nez Perce man was charged with killing a deer out of season in a National Forest beyond the boundaries of the reservation but within tribal land ceded in the Treaty with the Nez Perces, $1855 .^{36}$ The question addressed only the entitlement to hunt on these ceded lands. In these proceedings, the Court used the repudiations ${ }^{37}$ of the conclusion reached in Ward v. Race Horse $e^{38}$-i.e., that the Admission Act and the subsequent State Constitution of Wyoming impliedly repealed or abrogated all treaty rights for Indians within that State - to determine that "whatever the original scope of the reserved rights set forth in the Treaty of 1855 may be, they still exist unimpaired by subsequent agreement, treaty, Act of Congress, or the admission of Idaho to statehood."39 This, in combination with the deduction derived from the treaty council minutes that the National Forest lands under consideration were "open and unclaimed land" in accord with the 1855 treaty specifications, led the Court to declare that the right to hunt on "open and unclaimed land" still existed, regardless of the season. These results were obtained in a similar, out-of-season possession case (State v. Powaukee). ${ }^{40}$

State v. Tinno ${ }^{41}$ considered the taking of salmon by a member of the Shoshone-Bannock Tribe. The process - spear fishing - as well as the taking and the location of the fishing, were all in violation of Idaho State fishing regulations. The respondent's defense was based upon Article 4 of the Treaty with the Eastern Band of Shoshoni and Bannock, 1868, ${ }^{42}$ which promised an unqualified "right to hunt on the unoccupied lands of the United States." 43 The Court concluded that this Article should be read and considered to afford an unqualified fishing right as well. In addition, given the findings in Tulee v. Washington ${ }^{44}$ that supported fishing rights even where the pertinent treaty only indicated a qualified access to these resources, ${ }^{45}$ the Court required a clear demonstration of the efficacy of any State program of species preservation that might potentially regulate this treaty fishing right.

In a case of hunting on private lands, an Idaho Kootenai woman claimed an aboriginal right to hunt when charged with both killing deer out of season and killing the animals with the aid of an artificial light (State v. Coffee). ${ }^{46}$ The Court concluded that such a right to hunt existed and that the Idaho Kootenai were not signatories to the Treaty with the Flatheads, etc., $1855 .^{47}$ However, they accepted the Indian Claims Commission's finding in Kootenai Tribe or Band of Indians of the State of Idaho v. United States ${ }^{48}$ that the Idaho Kootenai's aboriginal title had been extinguished through the Senate ratification process of that treaty, even though the Idaho Kootenai had not participated in that transaction. As a result, the Kootenai "as with the signatory tribes, were left a right to hunt upon open and unclaimed land"49 but not upon private land. The motion to dismiss was denied. Justice Donaldson, in lone dissent, proposed that "the 
ratification of a treaty that did not purport to affect the Idaho Kootenai" ${ }^{50}$ could not extinguish their hunting rights. He inferred, from the absence of any hunting or fishing rights remarks within the 1957 Indian Claims Commission decision to extinguish the tribe's right of possession, that there should have been no effect upon other aboriginal rights - including the right to hunt-since these rights were reserved by the tribe.

Finally, State v. Cutler $^{51}$ involved the killing of elk on a game management preserve situated on State-owned land. The defendants, all Shoshone-Bannock Tribe members, claimed that the Treaty with the Eastern Band of Shoshoni and Bannock, 1868, ${ }^{52}$ reserved their hunting rights. The Court examined the Arthur, Tinno, and Coffee cases for guidance, as well as the minutes from the Fort Bridger treaty council, to uncover "historical circumstantial evidence" ${ }^{53}$ for insight into the Indians' understanding during those negotiations that their gathering rights would diminish. Further, the physical attributes of the management area precluded any possible misunderstanding that the area was "unoccupied lands of the United States," as specified for these hunting rights in Article 4 of the treaty. ${ }^{54}$ As a result, the Court affirmed the conviction. In a dissent similar to that in Coffee, two Justices questioned, inter alia, the Court's conclusion that the land was not "unoccupied." The findings in Tinno had supported the notion that these lands were "unsettled" and thus an available hunting area. The Justices could find "no qualitative factual distinction which makes a state wildlife area [i.e., the area in Cutler] materially different from a national forest [the river location under consideration in Tinno was within the Challis National Forest],"55 especially since the modifications to the wildlife area that the Court found critical to the "unoccupied" specification are also evidenced in national forests.

These six cases before the Supreme Court of Idaho reveal, over a forty-year period, one among many fundamental areas of difficulty that the tribes and States face. In each of the cases identified in Table 1, treaty parameters were relied upon to address these questions. Frequently, the tribes only have these points of reference available to define the gathering or other rights pledged in these documents. ${ }^{56}$

\section{Table 1 and case selection}

Those cases from any State Court system that cited any recognized Indian treaty were selected by using each treaty's Statutes at Large reference ${ }^{57}$ to identify case entries in the "Federal and State Cases" option of the full LexisNexis online database. The Web-based Westlaw Campus suite was interrogated for all relevant Statutes at Large references as well. ${ }^{58}$ In this manner, Table 1 identifies the 428 citations to these 131 ratified Indian treaties or supplementary treaties found in 246 State Court opinions for the years 1800 (Commonwealth v. Coxe $)^{59}$ to 2004 ( $J \&$ \& Aircraft Mobile T Hangars, Inc. v. Johnson County Airport Authority). ${ }^{60}$

Table 1 is an aggregate of the following data:

- The ratified treaty number, assigned by the Department of State, ${ }^{61}$ of each of the relevant treaties that has been cited in the opinion of any State Court. Supplementary treaties that 
affected the parameters of previous instruments are identified by decimal additions to the affected treaty's ratified treaty number. ${ }^{62}$ Table 1 contains six such supplementary treaty examples: $123.1 ; 152.1,253.1 ; 291.1 ; 293.1$, and $327.1 .^{63}$

- The name(s) of the participating tribe(s), with an expansion of the "etc." found in the titles of many treaties in Kappler's work into a complete list of parties. For example, ratified treaty number 10 is the Treaty with the Wyandot, etc., 1785, ${ }^{64}$ and the entry for this document in Table 1 identifies as signatories the Wyandot as well as the Delaware, Chippewa, and Ottawa.

- The signing date of the treaty, taken from each treaty's entry in volume 2 of Kappler's Indian Affairs: Laws and Treaties, or from the listed alternative sources.

- The treaty page number in Indian Affairs: Laws and Treaties, or in the alternative resources.

- The Statutes at Large citation for the treaty, if any.

- The case title and year of the citing State Court case, arranged chronologically within each treaty.

- The reporter citation for this case.

- The State Court in which the citation appeared. The possible venues include Appellate Court ("App. Ct., Ill."; $N=1$ ); the Appellate Division of a Supreme Court ("App. Div., N.Y."; $N=8$ ); County Court ("County Ct., N.Y. Chautauqua"; $N=1$ ); Court of Appeals (e.g., "Ct. App., Ariz."; $N=56$ ); Court of Claims ("Ct. Cl., N.Y.”; $N=5$ ); Court of Criminal Appeals ("Ct. Crim. App., Okla."; $N=7$ ); Tax Court (“Tax Ct., Or.”; $N=2$ ); or Supreme Court (e.g., "Sup. Ct., Idaho”; $N=348$ ).

\section{Conclusions}

This is a broad collection of cases, encompassing many issues, with proceedings heard in 30 States. ${ }^{65}$ The cited instruments range over the complete ensemble of Department of State recognized treaties, from the very first (ratified treaty number 1: The Great Treaty of 1722 between the Five Nations, the Mahicans, and the Colonies of New York, Virginia, and Pennsylvania) to the very last (ratified treaty number 374: the Treaty with the Nez Perces, 1868). Each of these States has been required to address within their jurisdictions one or more Indian treaty issues, just as the federal government has had to do within its larger domain. The recurring major issues - as illuminated above by the six gathering rights cases before the Supreme Court of Idaho-take time to solve at the State, ${ }^{66}$ as well as at the federal, level. One index of this activity might be demonstrated by comparing the number of court appearances before similar courts. The quantity of cases listed in Table 1 before the Supreme Court of Oklahoma $(N=47)$ might well be expected from the evolution of Indian Territory ${ }^{67}$ or from the 67 tribes that have resided within Oklahoma. ${ }^{68}$ The Supreme Court of Washington State, however, has heard more suits $(N=67)$ than the Supreme Court of Oklahoma.

Nonetheless, equitable solutions are frequently delayed or never found. Fairbanks, ${ }^{69}$ in his remarks upon the precariousness of treaty rights, noted, "Native American peoples maintain 
that their treaties ought to be honored as solemn contracts between nations. The various States, seemingly at the behest of special interest groups, consistently refuse or neglect to honor treaty provisions." ${ }^{\text {"T0 }}$ Thus, the State Courts have become an important venue for seeking solutions to sovereignty conflicts. The two centuries of litigation collated here would support such a hypothesis.

Further, these treaty questions are not solely an issue for State governments in the western half of the nation. Absent Minnesota, through which the Mississippi River flows, 12 of the remaining 29 States represented in Table 1 are east of this traditional national dividing line. Thus, treaty issues are the concern of all jurisdictions. Recently, State-tribal cooperative agreements $^{71}$ have become a mechanism to address fundamental concerns that have traditionally caused friction between these two sovereigns. Meyers and Smith identify such accords for environmental protection, natural resources, taxation, law enforcement, and delivery of social services. These are precisely where "the litigation mode has not proven the best means to resolve the core uncertainties and distrust between states and tribes." ${ }^{, 2}$ Their case study describes one of the major accomplishments of the Colorado Ute Water Rights Agreement. This agreement was "the first Indian water rights settlement passed by Congress that fully addresses how an Indian reserved water right will look and be treated if used offreservation." ${ }^{, 3}$ Such joint endeavors should more easily address many remaining treaty questions.

Finally, five treaties in Table 1 (ratified treaty numbers $1,3,116,125$, and 238) have been cited only in the opinions of State Courts and have never been referenced in a judgment of a federal court. The relevance of these contracts before the State Courts today, however, may be seen in the case, In re Baby Boy D (Oklahoma). ${ }^{74}$ In Baby Boy D, the council proceedings of ratified treaty number 3 ( $A$ Treaty Held at the Town of Lancaster, By the Honourable the Lieutenant-Governor of the Province, and the Honourable the Commissioners for the Province of Virginia and Maryland, with the Indians of the Six Nations in June, 1744) ${ }^{75}$ were cited as part of a demonstration of Indian rejection of "the insensitive precedent [that] had been cast to destroy Indian culture and tribal cohesiveness by removing Indian children from their families and tribal environments." ${ }^{, 76}$ In this suit, a 140-year-old treaty was employed just as three previously uncited treaties were referenced in the United States Supreme Court case of Minnesota v. Mille Lacs Band of Chippewa Indians. ${ }^{77}$ Charles J. Wilkinson has noted the Courts' reliance upon these instruments: he has stated that " $\mathrm{t}]$ he field of Indian law rests mainly on the old treaties and treaty substitutes." ${ }^{, 78}$ It is clear from the abundance of cases cited in this article that the Courts of 30 State jurisdictions - just as of the federal level-concur with this assessment. These arenas have been required to reconcile these treaties between the Indian Nations and the federal government within past and contemporary litigation. These State Courts will be called upon again in the future to resolve the contents of these documents.

\section{Acknowledgment}

We thank Francis Paul Prucha, S.J., for his constructive comments regarding this article. 


\section{Appendix A. Treaties of the Pre-Revolutionary War Period}

The first three recognized treaties in Table 1 -ratified treaty numbers 1,3 , and 7 -were negotiated by the British before the Revolutionary War but are acknowledged by the Department of State as binding treaties with the tribes. Abbreviations for two specific sources to each of these three treaties are indicated below, and these notations are used in Table 1.

- Treaty \#1: The Great Treaty of 1722 between the Five Nations, the Mahicans, and the Colonies of New York, Virginia, and Pennsylvania. ${ }^{79}$ Abbreviated in Table 1 as EAID 9, 103 and $N Y 5,657$.

- Treaty \#3: A Treaty Held at the Town of Lancaster, by the Honourable the LieutenantGovernor of the Province, and the Honourable the Commissioners for the Province of Virginia and Maryland, with the Indians of the Six Nations in June, $1744{ }^{80}$ Abbreviated in Table 1 as EAID 2, 77 and Franklin, 41.

- Treaty \#7: Treaty of Fort Stanwix, or The Grant from the Six Nations to the King and Agreement of Boundary Line-Six Nations, Shawnee, Delaware, Mingoes of Ohio, $1768 .^{81}$ Abbreviated in Table 1 as EAID 10, 541 and NY 8, 111.

\section{Notes and References}

1. Bernholz, C. D. (2004). American Indian treaties and the Supreme Court: A guide to treaty citations from opinions of the United States Supreme Court. Journal of Government Information, 30, 318-431.

2. Bernholz, C. D. (in preparation). American Indian treaties and the lower Federal Courts: A guide to treaty citations from opinions of the lower United States Federal Court system.

3. Bernholz, C. D., \& Weiner, R. J., Jr. (in preparation). American Indian treaties in the opinions of the Courts of Claims.

4. Bernholz, C. D. (2001). The absent American Indian treaties: A guide to treaties never referenced at the Federal Court level. Journal of Government Information, 28, 171-178;

Bernholz, C. D. (2002). The absent American Indian treaties: An update. Journal of Government Information, 29, 39-41. In another study, it was found that the Territorial Courts adjudicated questions pertaining to over 50 Indian treaties [Bernholz, C. D. (in preparation). American Indian treaties in the Territorial Courts: A guide to treaty citations from opinions of the Territorial Court Systems].

5. Five treaties in Table 1 have been cited only in the opinions of State Courts and have never been referred to in an opinion of a federal court. They are ratified treaty numbers 1 and 3, The Great Treaty of 1722 between the Five Nations, the Mahicans, and the Colonies of New York, Virginia, and Pennsylvania (cited in Gregory v. Baugh, 25 Va. 611 (1827), Virginia) and A Treaty Held at the Town of Lancaster, by the Honourable 
the Lieutenant-Governor of the Province, and the Honourable the Commissioners for the Province of Virginia and Maryland, with the Indians of the Six Nations in June, 1744 (In re Baby Boy D, 742 P.2d 1059 (1985), Oklahoma); ratified treaty number 116, the Treaty with the Creeks, 1821 [Minter v. State, 158 Ga. 127 (1924), Georgia]; ratified treaty number 125, the Treaty with the Creeks, $1825[\mathrm{~J} \&$ M Aircraft Mobile T Hangars, Inc. v. Johnson County Airport Authority, 269 Ga. App. 800 (2004), Georgia]; and ratified treaty number 238, the Treaty with the Stockbridge and Munsee, 1839 [State v. Davids, 182 Wis.2d 186 (1994) and State v. Davids, 194 Wis.2d 386 (1995), Wisconsin]. See the Appendix for sources for the first two treaties. The Treaty with the Creeks, 1821, the Treaty with the Creeks, 1825, and the Treaty with the Stockbridge and Munsee, 1839, appear in Kappler, C. J. (1904). Indian affairs: Laws and treaties: Vol. 2, treaties. Washington, DC: Government Printing Office 1904, pp. 195-197, 214-217, and 529-531. Also available at: http:/digital.library.okstate.edu/ kappler/Vol2/treaties/cre0195.htm; http:/digital.library.okstate.edu/kappler/Vol2/treaties/ cre0214.htm; and http://digital.library.okstate.edu/kappler/Vol2/treaties/sto0529.htm, respectively.

6. Worcester v. Georgia, 31 U.S. 515 (1832).

7. See, for example, Article 5 of the Treaty with the Cherokees, 1835 (Kappler, p. 442; also available at: http://digital.library.okstate.edu/kappler/Vol2/treaties/che0439.htm): "The United States hereby covenant and agree that the lands ceded to the Cherokee nation in the forgoing article shall, in no future time without their consent, be included within the territorial limits or jurisdiction of any State or Territory.”

8. The Kansas Indians, 72 U.S. 737 (1867).

9. The Kansas Indians case is of interest, because it is composed of three separate actions consolidated before the Court. This suite, which investigated questions of taxation within two counties of Kansas against federal treaty assurances given to the Shawnee, Wea, and Miami tribes, came on appeal from the Supreme Court of Kansas. The opinion from the first of these lower cases-Blue-Jacket v. Commissioners of Johnson County (3 Kan. 299, (1865)) - is identified in the attached Table 1 and that text cites the Treaty with the Shawnee, 1854. See Kappler (pp. 618-626). Also available at: http://digital.library. okstate.edu/kappler/Vol2/treaties/sha0618.htm. Blue Jacket was a Shawnee signatory to the 1854 treaty (Kappler, p. 623).

10. The New York Indians, 72 U.S. 761 (1867).

11. McClanahan v. Arizona State Tax Commission, 411 U.S. 164 (1973).

12. Gregory v. Baugh.

13. State v. Big Sheep, 75 Mont. 219 (1926) and State v. Brave Heart, 326 N.W.2d 220 (1982).

14. Montoya v. Bolack, 70 N.M. 196 (1962).

15. Metlakatla Indian Community v. Egan, 362 P.2d 901 (1961).

16. The Metlakatlans are Tsimshian Indians, originally from British Columbia, Dunn, J. A., \& Booth, A. (1990). Tsimshian of Metlakatla, Alaska. In W. C. Sturtevant \& W. Suttles (Eds.), Handbook of North American Indians, Vol. 7, Northwest Coast, (pp. 294-297). Washington, DC: Smithsonian Institution. 
17. Metlakatla Indian Community v. Egan, p. 908.

18. Metlakatla Indian Community v. Egan, 369 U.S. 45 (1962). The legislation to assist the Metlakatla specified that these Islands were "to be held and used by them in common, under such rules and regulations, and subject to such restrictions, as may be prescribed from time to time by the Secretary of the Interior" ( $§ 15,26$ Stat. 1095, 1101; emphasis added). See Tiller, V. E. E. (Ed.). (1996). American Indian Reservations and Trust Areas (pp. 22-23). Albuquerque, NM: Tiller Research Inc., for a description of the Annette Island Reserve.

19. Byers v. We-wa-ne, 86 Ore. 617 (1917).

20. Strawberry Valley Cattle Co. v. Chipman, 13 Utah 454 (1896).

21. In re Baby Boy $D$.

22. State ex rel. May v. Seneca-Cayuga Tribe, 711 P.2d 77 (1985).

23. State v. Webster, 114 Wis.2d 418 (1983).

24. The term "gathering rights" is used in this note as a generic term to identify and include any form of usufructuary right.

25. Minnesota v. Mille Lacs Band of Chippewa Indians, 526 U.S. 172 (1999).

26. See McClurken, J. M. (2000). Fish in the lakes, wild rice, and game in abundance: Testimony on behalf of Mille Lacs Ojibwe hunting and fishing rights. East Lansing, MI: Michigan State University Press, for an interesting collection of testimony regarding this United States Supreme Court case.

27. State v. Keezer, 292 N.W.2d 714 (1980).

28. Two cases - State v. McConville, 65 Idaho 46 (1943) and State v. Arthur, 74 Idaho 251 (1953) - cite a treaty (ratified treaty number 291, the Treaty with the Nez Perces, 1855; Kappler, pp. 702-706; also available at: http://digital.library.okstate.edu/kappler/Vol2/ treaties/nez0702.htm) that was affected by a supplementary treaty (ratified treaty 323 , the Treaty with the Nez Perces, 1863; pp. 843-848; also available at: http:/digital.library.okstate.edu/kappler/Vol2/treaties/nez0843.htm) that is identified in Table 1 as ratified treaty number 291.1.

29. State v. McConville.

30. See Kappler (pp. 702-706). Also available at http://digital.library.okstate.edu/kappler/ Vol2/treaties/nez0702.htm

31. These are the Treaty with the Nez Perces, 1863 (Kappler, pp. 843-848; also available at: http://digital.library.okstate.edu/kappler/Vol2/treaties/nez0843.htm), and the Treaty with the Nez Perces, 1868 (pp. 1024-1025; also available at: http://digital.library.okstate.edu/ kappler/Vol2/treaties/nez1024.htm).

32. Tulee v. Washington, 315 U.S. 681 (1942).

33. The pivotal instrument in Tulee, the Treaty with the Yakima, 1855 (Kappler, pp. 698-702; also available at: http://digital.library.okstate.edu/kappler/Vol2/treaties/yak0698.htm), was concluded at the same council site by the same negotiating team led by Isaac I. Stevens, the Governor and Superintendent of Washington Territory, two days earlier than the Treaty with the Nez Perces, 1855.

34. State v. McConville, p. 50.

35. State v. Arthur. 
36. See Kappler (pp. 702-706; also available at: http:/digital.library.okstate.edu/kappler/ Vol2/treaties/nez0702.htm).

37. See United States v. Winans, 198 U.S. 371 (1905); Winters v. United States, 207 U.S. 564 (1908); and Seufert Bros. Co. v. United States, 249 U.S. 194 (1919).

38. Ward v. Race Horse, 163 U.S. 504 (1896).

39. State v. Arthur, pp. 260-261.

40. State v. Powaukee, 78 Idaho 257 (1956).

41. State v. Tinno, 94 Idaho 759 (1972).

42. The text of this instrument is available in Kappler (pp. 1020-1024). Also available at: http://digital.library.okstate.edu/kappler/Vol2/treaties/sho1020.htm

43. See Kappler, p. 1021; emphasis added. Also available at: http://digital.library.okstate.edu/ kappler/Vol2/treaties/sho1020.htm

44. Tulee v. Washington.

45. See the Treaty with the Yakima, 1855 (Kappler, pp. 698-702; also available at: http:// digital.library.okstate.edu/kappler/Vol2/treaties/yak0698.htm). Article 3 of this treaty qualifies the fishing right by stating that it may be carried out "in common with the citizens of the Territory" (p. 699).

46. State v. Coffee, 97 Idaho 905 (1976).

47. The treaty may be found in Kappler (pp. 722-725). Also available at: http:// digital.library.okstate.edu/kappler/Vol2/treaties/fla0722.htm

48. Kootenai Tribe or Band of Indians of the State of Idaho v. United States, 5 Ind. Cl. Comm. 456 (1957).

49. State v. Coffee, p. 913, emphasis added.

50. State v. Coffee, p. 916.

51. State v. Cutler, 109 Idaho 448 (1985).

52. See Kappler (pp. 1020-1024). Also available at: http:/digital.library.okstate.edu/kappler/ Vol2/treaties/sho1020.htm

53. State v. Cutler, p. 453.

54. Kappler, p. 1021.

55. State v. Cutler, p. 459.

56. Another suite of eight cases from the State of Washington-Department of Game v. Puyallup Tribe, Inc., 70 Wash.2d 245 (1967); Department of Game v. Puyallup Tribe, Inc., 80 Wash.2d 561 (1972); Department of Game v. Puyallup Tribe, Inc., 86 Wash.2d 664 (1976); Puget Sound Gillnetters Association v. Moos, 88 Wash.2d 677 (1977); Puget Sound Gillnetters Association v. Moos, 92 Wash.2d 939 (1979); State v. Satiacum, 50 Wash.2d 513 (1957); State v. Moses, 79 Wash.2d 104 (1971); and State v. Courville, 36 Wash. App. 615 (1983)-that collectively cited 9 different treaty documents including a 1797 Seneca instrument for lands within New York State, also portrays the ongoing debates and seemingly disparate decisions. These cases have in common the "right of taking fish at usual and accustomed grounds and stations" that was assured in nine treaties negotiated in 1854 and 1855 by Isaac I. Stevens, the Governor of Washington Territory. Eight out of these nine documents are cited in the opinions of these cases. See Prucha, F. P. (1984). The Great Father: The United States Government and the American Indians 
(pp. 402-409). Lincoln, NE: University of Nebraska Press; Prucha, F. P. (1994). American Indian treaties: The history of a political anomaly (pp. 250-255). Berkeley, CA: University of California Press, for a discussion of these proceedings.

57. Volumes of Statutes at Large are now available on the Library of Congress's Century of lawmaking for a new nation page. Available at: http://memory.loc.gov/ammem/amlaw/ lwsl.html. The texts of all treaties cited in Table 1 are available at this site.

58. This is an expanded process, in comparison to the previous analyses (Bernholz, 2001, 2002, and 2004) that used Shepard's Federal Statute Citations (Shepard's Federal Statute Citations: Statute Edition Supplement, 1996-2001: Vol. 4 (2001). Colorado Springs, CO: Lexis Publishing; and Shepard's Federal Statute Citations: Vol. 6 (8th ed.). (1996). Colorado Springs, CO: Shepard's/McGraw-Hill Inc.) as a case identification tool along with the LexisNexis resource. Shepard's has the advantage of editor-deduced Statutes at Large citations for materials contained in opinion texts; in many early cases, the individual treaty Statutes at Large reference was not given. This supplemental information is not accessible when searching any database for a specific text target, such as " 10 Stat. 1053" for the Treaty with the Shawnee, 1854. Thus, case selection in this guide is bound by the completeness of the LexisNexis and the Westlaw online databases.

59. Commonwealth v. Coxe, 4 U.S. 170 (1800).

60. $J \&$ M Aircraft Mobile T Hangars, Inc. v. Johnson County Airport Authority.

61. See Ratified Indian Treaties, 1722-1869 (1966). Washington, DC: National Archives and Records Service.

62. Bernholz, C. D. (in preparation). Adjusting American Indian treaties: A guide to supplemental article and supplementary treaty citations from opinions of the United States Federal Court system.

63. The corresponding affecting treaties are ratified treaty numbers 186, 182, 269, 323, 351, and 330, respectively. The 11 court cases are assigned positions in both treaty positions within the Table. For example, State ex rel. May v. Seneca-Cayuga Tribe is denoted as a case under ratified treaty number 123.1 to show that the Court's opinion cited this 1833 supplementary treaty to the 1824 , ratified treaty number 123 document. The case is also placed under ratified treaty number 186, i.e., at its original Department of State ordinal position. The numbers of citations and of opinions were incremented only once for each unique case within these six sets of affected and supplementary treaties.

64. Kappler, pp. 6-8.

65. The full array of States is Alabama, Alaska, Arizona, California, Georgia, Idaho, Illinois, Indiana, Kansas, Maryland, Michigan, Minnesota, Missouri, Mississippi, Montana, New York, New Mexico, North Carolina, North Dakota, Ohio, Oklahoma, Oregon, Pennsylvania, South Dakota, Texas, Utah, Virginia, Washington, Wisconsin, and Wyoming.

66. State v. Coffee. The case, regarding hunting on private lands by an Idaho Kootenai woman, proceeded through the local Magistrate (State v. David, No. M-2041, Magistrate Court, Boundary County, Idaho. Filed August 21, 1973) and through the District Court of Appeal (State v. Coffee, No. M-2041, District Court, Boundary County, Idaho. Filed September 12, 1975) before reaching the Supreme Court of Idaho. The deer were shot in October 1972. 
67. Gittinger, R. (1917). The formation of the State of Oklahoma (1803-1906). Berkeley, CA: University of California Press.

68. Wright, M. H. (1986). A guide to the Indian tribes of Oklahoma. Norman, OK: University of Oklahoma Press. See her map on p. 16.

69. Fairbanks, R. A. (1995). Native American sovereignty and treaty rights: Are they historical illusions? American Indian Law Review, 20, 141-149.

70. Fairbanks, p. 147.

71. Meyers, H., \& Smith, C. (2004). American Indian law deskbook (3rd ed.) (pp. 500-531). Boulder, CO: University Press of Colorado.

72. Meyer, \& Smith, p. 500.

73. Meyer, \& Smith, p. 521.

74. In re Baby Boy D.

75. Vaughan, A. T., \& Kent, D. H. (Eds.). (1984). Early American Indian documents: Treaties and laws, 1607-1789, vol. 2: Pennsylvania treaties, 1737-1756 (pp. 77-110). Washington, DC: University Publications of America;

Van Doren, C., \& Boyd, J. P. (Eds.). (1938). Indian treaties printed by Benjamin Franklin, 1736-1762 (pp. 41-79). Philadelphia, PA: The Historical Society of Pennsylvania.

76. In re Baby Boy D, p. 1072.

77. Minnesota v. Mille Lacs Band of Chippewa Indians.

78. Wilkinson, C. F. (1987). American Indians, time, and the law: Native societies in a modern constitutional democracy (p. 120). New Haven, CT: Yale University Press.

79. Vaughan, A. T., \& Graymont, B. (Eds.). (1996). Early American Indian documents: Treaties and laws, 1607-1789, vol. 9: New York and New Jersey treaties, 1714-1753 (pp. 103-127);

O'Callaghan, E. B. (Ed.). (1855). Documents relative to the colonial history of the State of New York, Vol. 5 (pp. 657-681). Albany, NY: Weed, Parsons, and Co.

80. Vaughan \& Kent, pp. 77-110;

Van Doren \& Boyd, pp. 41-79.

81. Vaughan, A. T., \& Graymont, B. (Eds.). (2001). Early American Indian documents: Treaties and laws, 1607-1789, vol. 10: New York and New Jersey treaties, 1754-1775 (pp. 541-566). Bethesda, MD: University Publications of America; O'Callaghan, E. B. (Ed.). Documents relative to the colonial history of the State of New York, vol. 8 (pp. 111-137). Albany, NY: Weed, Parsons, and Co. 